\title{
Redistribuição de renda, pobreza e desigualdade territorial no Brasil
}

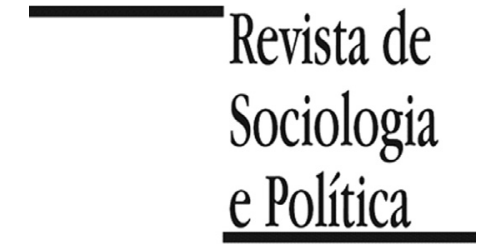

DOI 10.1590/1678-987317256307

\author{
Victor Araújo e Paulo Flores
}

Resumo

Políticas redistributivas centralizadas podem induzir resultados desiguais entre os territórios? Respondemos afirmativamente a esta questão, apresentando evidências de que a transferência de renda para indivíduos, promovida por uma política social em que a arrecadação e o gasto são centralizados, como o Benefício de Prestação Continuada (BPC), não se traduz automaticamente em redistribuição de recursos entre territórios. Embora a adoção de políticas de redistribuição de renda no nível interpessoal seja importante para suavizar as tendências de extrema pobreza, estes ganhos em bem-estar não reduzem mecanicamente as disparidades entre as regiões brasileiras. Nas situações em que fatores exógenos à estrutura fiscal impedem que a alocação de recursos siga a distribuição espacial da necessidade, políticas redistributivas centralizadas podem colaborar para o aumento da desigualdade territorial.

PALAVRAS-CHAVE: políticas públicas; transferência de renda; estrutura fiscal; desigualdade territorial; pobreza.

Recebido em 22 de Maio de 2016. Aceito em 29 de Novembro de 2016.

\section{Introdução ${ }^{1}$}

\footnotetext{
1 Agradecemos aos comentários de Marta Arretche, Rogério Barbosa, Luiza Meira Bastos, Eduardo Lazzari, Patrícia Nabuco Martuscelli, Thiago Meireles, Gabriela Thomazinho e dos pareceristas anônimos da Revista de Sociologia e Política. O pesquisador Victor Araújo conta com o apoio da Fundação de Amparo à Pesquisa do Estado de São Paulo (FAPESP), processo ${ }^{\circ}$ 2016/23215-0.

2 Ver Beramendi (2012), Beramendi e Rueda (2014), Kazepov e Barberis (2013), Padovano (2007), Treisman (2007) e Wibbels (2005).
}

$\mathrm{N}$ a última década, o debate sobre redistribuição de renda e desigualdade entre regiões ganhou proeminência na área de economia política. Passou-se a teorizar sobre os efeitos do agravamento ou da atenuação de desigualdades regionais, tendo como referência o grau observado de centralização das atribuições (1) legislativas, (2) administrativas e (3) fiscais, e seus efeitos sobre a redistribuição de recursos entre territórios ${ }^{2}$. Neste trabalho, a pergunta mais ampla que se pretende responder é: em que medida fatores exógenos à estrutura fiscal contribuem para a distorção do efeito redistributivo entre regiões produzido por políticas de renda centralizadas?

Embora parte da literatura que investiga essa temática utilize o Produto Interno Bruto (PIB) per capita como dimensão de análise, para economias extremamente desiguais esta medida não consegue captar parte importante da variação nas condições de bem-estar social (Sen 1973; Rocha 1998; Kakwani \& Son 2008). Sendo assim, assumimos que o fenômeno da desigualdade territorial deve ser entendido como a capacidade desigual de as regiões em um dado arranjo político proverem recursos de subsistência aos seus cidadãos. Mais especificamente, definimos desigualdade territorial como a concentração desigual de indivíduos vulneráveis em unidades territoriais comparáveis, sendo a vulnerabilidade função do número de indivíduos extremamente pobres em um dado território.

Não são desprezíveis as consequências deste fenômeno. Além de produzir efeitos sobre a espacialização da riqueza nacional (Azzoni 2001), a desigualdade entre regiões influencia a dinâmica interna do mercado de trabalho (Manso, Barreto \& França 2010) e os fluxos de migração interna (Cunha 2015), afetando a estabilidade política, social e econômica de um determinado país (Levy \& Chowdhury 1995). Mesmo que alguns autores sugiram que o aumento médio das rendas vem colaborando para uma tendência de redução das dispari- 
dades regionais (Hoffmann 2006; Silveira-Neto \& Azzoni 2012), evidências recentes demonstram que o acesso a recursos de subsistência permanece desigualmente distribuído entre as regiões brasileiras (Soares et al., 2015).

Analistas têm sugerido que a centralização da arrecadação e transferências no governo central contribui para a redução da desigualdade entre territórios (Arretche 2010; Beramendi 2012). Na mesma direção, argumenta-se que a descentralização pode gerar problemas de coordenação entre atores no processo decisório, diferenciar critérios de elegibilidade por regiões e legitimar institucionalmente modelos divergentes de políticas sociais - o que, por conseguinte, conduziria a diferentes resultados regionais e aumentaria a desigualdade (Kazepov \& Barberis 2013). Tratam-se, na realidade, de argumentos derivados da concepção de que formas difusas de governança de políticas tendem a produzir resultados espacialmente descontínuos (Allen \& Cochrane 2007).

Do ponto de vista lógico, o argumento em torno de tais proposições é bastante atraente. Em federações com estrutura fiscal descentralizada, as regiões mais ricas arrecadariam mais e enfrentariam um quadro de pobreza menos agudo, dispondo de recursos para redistribuir entre os cidadãos por meio de políticas sociais. As regiões pobres, por sua vez, teriam menos capacidade de arrecadação e maior incidência de pobreza, posta a menor capacidade destes governos locais de retirar indivíduos da condição de vulnerabilidade social.

Por outro lado, se há desigualdade entre regiões e o sistema de arrecadação é centralizado, as regiões mais ricas arrecadarão e repassarão parcelas mais substantivas de recursos ao governo central do que as regiões pobres, de menor potencial econômico e menor capacidade arrecadatória e de gasto. Sendo os critérios de elegibilidade e administração das políticas sociais também centralizados, a transferência de recursos se daria de acordo com a distribuição da necessidade no território. Ou seja, proporcionalmente, regiões pobres receberiam mais recursos do fundo de arrecadação comum do que as regiões ricas, justamente por concentrarem territorialmente um número maior de indivíduos vulneráveis, potencialmente elegíveis às políticas sociais do governo central. Dessa maneira, operaria um mecanismo redistributivo entre regiões intrínseco ao modelo centralizado de estrutura fiscal.

Neste trabalho, argumentamos que este raciocínio é insuficiente para derivar resultados acerca das políticas sociais. Analisando o Benefício de Prestação Continuada (BPC), mostramos que políticas redistributivas centralizadas podem produzir resultados desiguais entre os territórios. Entre 1996 e 2012, houve, por efeito do benefício, uma redução média de $7 \%$ ao ano no número de pessoas extremamente pobres no Brasil. No caso do Nordeste, a região com a maior proporção de pobres no país, ocorreu uma importante redução da proporção de extremamente pobres de 4,8\% ao ano, em média. O BPC passou de 346.219 beneficiários, em 1996, para 4.182.824 em 2015 (Ministério do Desenvolvimento Social (2015). Em termos monetários, em 1996, o programa pagava

${ }^{3}$ Valor corrigido pelo índice IGP-M (FGV) na data de referência de $1^{\circ}$ de dezembro de 2015. em benefícios o equivalente a $\mathrm{R} \$ 788.189 .856^{3}$. Esse montante chegou à casa dos bilhões em 2015, totalizando R \$ 39.645.659.124.

A redução da pobreza regional tem sido acompanhada, no entanto, do aumento da desigualdade entre as regiões, uma vez que as regiões continuam a contribuir de forma desigual para a concentração total de pobreza do país. Este fato se deve ao maior impacto da transferência de renda interpessoal nas regiões com menor concentração de indivíduos extremamente pobres. Como demonstraremos, uma estrutura fiscal com características centrípetas não é condição suficiente para que fluxos redistributivos no nível interpessoal se traduzam automaticamente na redistribuição de recursos entre regiões, dado que fatores exógenos à estrutura fiscal podem minar o potencial equalizador de políticas redistributivas. 
No caso específico do BPC, uma mudança nos seus critérios de elegibilidade - ocorrida em 2003 com a aprovação do Estatuto do Idoso - e uma tendência demográfica de longo prazo - efeito da ocorrência descontínua da transição demográfica nas regiões brasileiras - produz um efeito observado de concentração desproporcional de potenciais beneficiários em regiões mais ricas, impedindo que a transferência de recursos favoreça as regiões mais pobres e atenue a desigualdade territorial.

Além desta introdução e da conclusão, em seguida, discutimos os parâmetros político-econômicos que possibilitaram a adoção de medidas redistributivas no Brasil dos últimos 25 anos. Na terceira seção, mostramos o impacto do BPC sobre as tendências de pobreza regional. Por fim, na quarta seção, analisamos como a parcela de redução da pobreza explicada pelo benefício contribui para o aumento da desigualdade territorial observada no Brasil.

\section{A economia política da pobreza no Brasil pós 1988}

Não obstante o federalismo seja recorrentemente associado à reprodução da desigualdade entre territórios (Tiebout 1956; Wildavsky 1985; Buchanan 1995; Weingast 1995), não existe um padrão de resultados pré-determinados pela escolha deste modelo de organização do Estado (Beramendi 2007; Voigt \& Blume 2012; Wibbels 2005), sendo o nível de redistribuição de recursos entre os territórios uma consequência da estrutura fiscal adotada. É dizer que (1) o grau de centralização do sistema de tributos e (2) os mecanismos (políticas) de redistribuição entre as regiões definem o padrão de desigualdade territorial observado em um dado contexto (Beramendi \& Rueda 2014).

A variação dessa estrutura fiscal cria diferentes constrangimentos para a redistribuição de recursos entre as regiões (Beramendi 2012). É exatamente por isso que dentro de um mesmo modelo de organização de competências é possível observar contextos onde inexistem mecanismos de redistribuição e se verifica um grau elevado de desigualdade territorial (EUA), e contextos onde existem mecanismos para reduzir a assimetria de recursos entre os entes federados e constata-se menos desigualdade entre as regiões (Alemanha).

Os governos subnacionais precisam de meios para desenvolver suas próprias políticas. Por isso, a existência de fluxos de transferência de recursos das regiões ricas para as regiões mais pobres é crucial para a garantia de um território menos heterogêneo e desigual. Estes fluxos, por sua vez, só podem ser criados por meio da implementação de mecanismos específicos, de políticas propostas pela elite política com o objetivo de proceder à redistribuição de recursos (Gradus 1983).

No Brasil, a desigualdade territorial é um problema que remete às suas origens e perpassa muitas dimensões. A intenção de diminuir as disparidades regionais está na raiz do atual sistema federativo brasileiro adotado na Constituição de 1988 (Souza 2005). Neste sentido, por exemplo, alguns dos elementos centrípetos da estrutura fiscal brasileira têm possibilitado a oferta mais homogênea de serviços públicos no território nacional (Araújo 2015; Arretche 2010). Ainda assim, em muitas dimensões permanecem grandes distâncias entre as regiões. Isso nos remete à questão de que o fenômeno da desigualdade territorial pode ser tratado sob vários aspectos. Neste trabalho, de forma similar ao exercício realizado por Rocha (1998), examinamos esta questão utilizando como parâmetro a contribuição das regiões para a pobreza total no país.

No último decênio, diversos analistas apontaram os efeitos positivos da implementação de diferentes políticas redistributivas sobre a pobreza e a desigualdade de renda no Brasil (Barros, Foguel \& Ulyssea 2007; Barros, Carvalho \& Franco 2007; Sátyro \& Soares 2009; Neri \& Souza 2012). Ainda que 
${ }^{4}$ Sobre o processo de valorização real do salário mínimo pós-Plano Real, ver Flores (2017).

\footnotetext{
${ }^{5}$ A Constituição de 1988 determina que "a Assistência Social será prestada a quem dela necessitar, independente de contribuição à seguridade social" (Brasil 2015).

${ }^{6}$ Artigos 21 e 22 da Lei ${ }^{\circ}$ 8.742, 1993.

7 A idade mínima para solicitação do benefício inicialmente fixada em 70 anos abaixou para $67 \mathrm{com}$ a Lei ${ }^{\circ} 9.720$ de 30 de novembro de 1998; e de 67 para 65 , a partir de 2003, com a aprovação do Estatuto do Idoso. Para mais informações, ver Medeiros, Diniz e Squinca (2006) e Miranda (2013).

${ }^{8}$ Referimo-nos ao montante aferido em números absolutos. Em termos proporcionais, dado o sistema de tributação regressivo adotado no Brasil, os indivíduos mais pobres contribuem com uma maior parcela de seus rendimentos para o bolo da arrecadação federal.

9 A análise da autora compreende o período entre 1988 e 2010
}

recentemente a queda da desigualdade de renda tenha sido colocado em xeque por Medeiros, Souza e Castro (2015a; 2015b) e Milá (2015), existe consenso entre os especialistas de que os níveis de pobreza foram reduzidos drasticamente no Brasil.

Neste cenário, o Programa Bolsa Família (PBF) e o Benefício de Prestação Continuada (BPC) se destacam pela contribuição na redução do número de extremamente pobres. Os impactos do PBF têm sido extensivamente investigados por estudiosos das Ciências Sociais. O BPC, por seu turno, tem recebido menos atenção dos estudiosos, embora o benefício represente uma fatia de gastos em política social consideravelmente maior que o PBF. O valor pago (R\$ 788 em julho de 2015) a um beneficiário do BPC é mais de dez vezes o valor pago (R\$ 77 em julho de 2015) a um beneficiário do PBF. Além disso, o fato de o valor do BPC estar atrelado ao salário mínimo permite aos seus beneficiários o mesmo retorno pecuniário assegurado aos trabalhadores formalmente ligados ao mercado de trabalho. Assim sendo, a tendência de aumento do salário mínimo acima da inflação desde a implementação do Plano Real ${ }^{4}$ possibilitou um importante crescimento da renda de uma parcela da população socialmente vulnerável.

Apesar da redução da pobreza ser também uma função de variáveis como a oferta de vagas no mercado formal de trabalho (Araújo, Barone \& Alves de Brito 2015; Barros, Corseuil \& Leite 2000), aumento da escolarização (Menezes Filho \& Kirschbaum 2015) e da implementação de programas focalizados de transferência de renda (Soares 2012), benefícios de substituição de renda como o BPC também cumprem um importante papel na diminuição da concentração de pobreza regional.

O BPC é um dos vários elementos da Carta Magna de 1988 que inaugurou uma nova era de inclusão e proteção social no Brasil (Sátyro \& Cunha 2014). Prescrito no artigo $203^{5}$ da Constituição Federal de 1988 e regulamento pela Lei Orgânica da Assistência Social ${ }^{6}$ (LOAS), o BPC foi a primeira política de Estado implementada na nova república com o objetivo de atenuar o problema da desigualdade social e pobreza.

São elegíveis ao BPC pessoas idosas com $65 \operatorname{anos}^{7}$ ou mais e pessoas com deficiência que comprovem não ter condições de prover a própria manutenção nem a serem providas pela família (Brasil 1995). Em ambos os casos, o benefício de um salário mínimo mensal só é concedido mediante comprovação da condição de vulnerabilidade e para aqueles indivíduos que tenham renda familiar mensal per capita inferior a $1 / 4$ do salário mínimo. O financiamento da política ocorre por diversos mecanismos de tributação pelos quais pessoas e regiões mais ricas contribuem mais para o montante dos valores arrecadados ${ }^{8}$. Isto é, existe um mecanismo automático de transferência de renda às pessoas e regiões mais pobres.

O interstício entre 1988 e 1996 - este último, ano da implementação do BPC - foi marcado por um constante conflito entre a elite política a respeito dos parâmetros que deveriam nortear a distribuição do benefício. Como mostra Miranda (2013, p.442), no período que sucedeu sua implementação ${ }^{9}$, a dinâmica político-partidária exerceu um impacto significativo sobre o desenho do BPC. Além dos processos regulamentares instaurados pela própria burocracia, as decisões que definiram as condições de acesso ao benefício resultaram das preferências do Presidente da República e de sua coalizão de apoio no Congresso Nacional.

Entre 1996 e 2012 houve um aumento de mais de dez vezes no número de beneficiários, passando de 346.219, em 1996, para 3.771 .842 em 2012. O Gráfico 1 informa a proporção de benefícios existentes [A], entre 1996 e 2012, 
bem como o número de beneficiários no tempo [B], em cada região. Com média de $39,3 \%$ e 32,74\%, respectivamente, as regiões Nordeste e Sudeste são aquelas que detêm a maior proporção de beneficiários em todos os anos da série. As demais regiões permaneceram com uma proporção de beneficiários inferior a $10 \%$ do total de assistidos em todos os anos da série.

Essa tendência pode ser explicada, em primeiro lugar, pelo expressivo contingente populacional das duas regiões. No caso específico do Nordeste, há ainda a combinação entre o grande contingente populacional e a baixa renda per capita observada. Embora apenas pessoas com deficiência e idosos com mais de 65 anos possam acessar o benefício, a pior qualidade de vida das famílias

Gráfico 1 - Proporção de benefíciários [A] e número absoluto [B] do BPC por região (1996-2012).

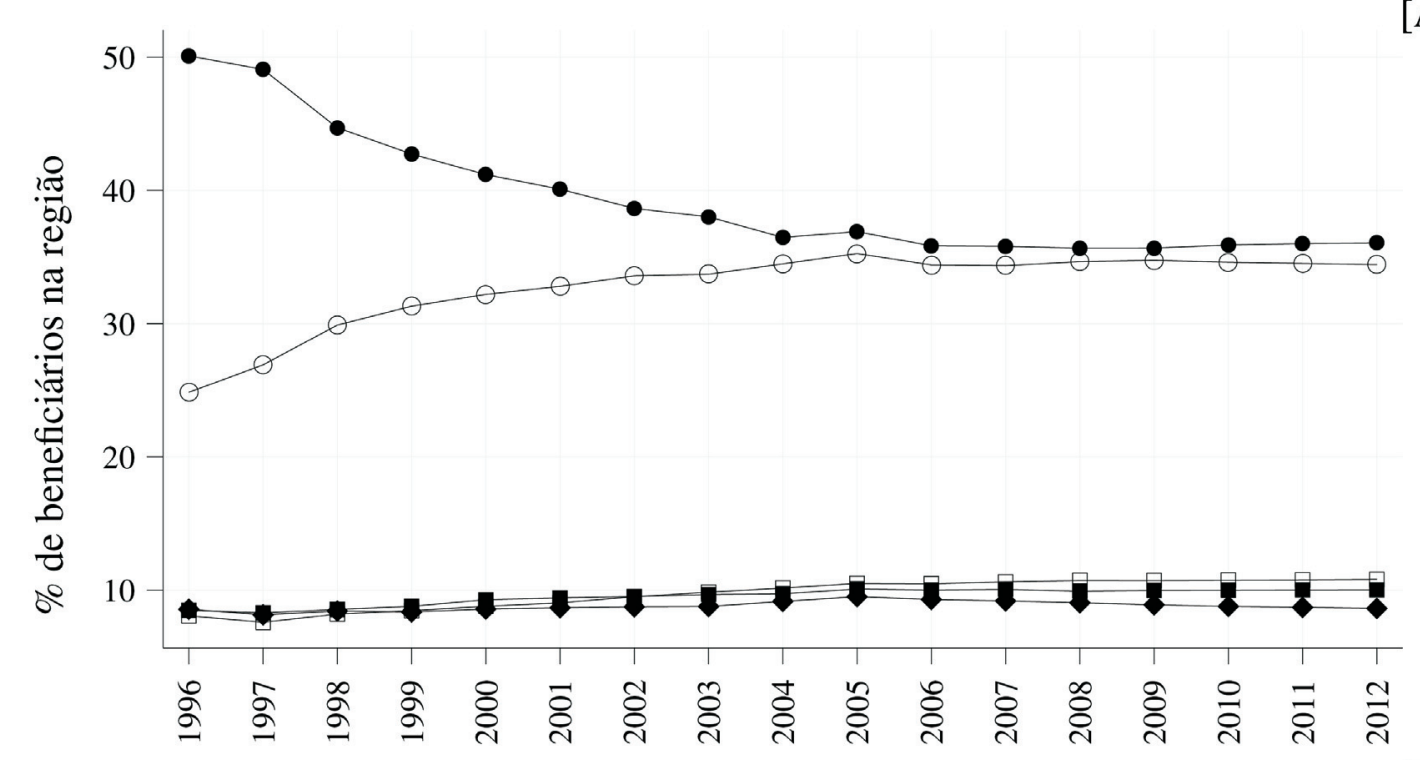

[A]

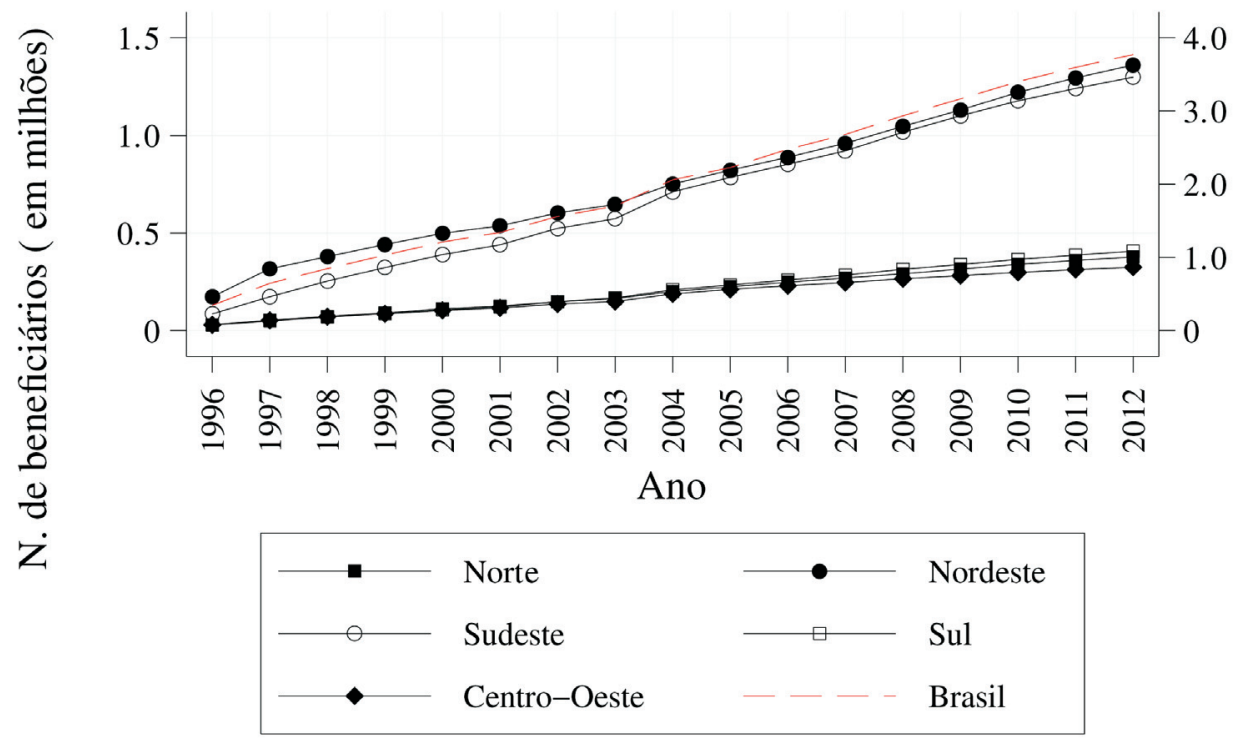

[B]

Fonte: Os autores, a partir das informações do Ministério do Desenvolvimento Social (2015). 
nessa região torna as pessoas nessas condições de vulnerabilidade potenciais dependentes do benefício. Dessa forma, as regiões onde existe maior concentração de pobreza são também aquelas onde os indivíduos são mais propensos a receber o benefício.

A variação do percentual de beneficiários do BPC entre as regiões produz efeitos sobre a desigualdade territorial no Brasil. Este é um aspecto de importância crucial para o argumento desenvolvido neste trabalho. Retornaremos a este ponto na quarta seção. Antes disso, é preciso considerar os efeitos potenciais do benefício sobre a proporção de pobres observada no tempo. Se os beneficiários do BPC, indivíduos considerados extremamente pobres, passam a ter garantia de uma renda mensal mínima, é razoável supor que as tendências de pobreza regional são afetadas pelo impacto dessa política. Este será o tema de investigação da próxima seção.

\section{Benefício de Prestação Continuada e Negativos de Pobreza}

Não existe nenhum argumento que possa desmobilizar as incontestáveis evidências de que a parcela extremamente pobre da população diminuiu no Brasil nos últimos 20 anos (Rocha 2013). Não obstante a clareza dos resultados observados, a redução do número de pessoas pobres não pode ser explicada por apenas uma variável, tratando-se de um processo multidimensional (Kageyama \& Hoffman 2006).

Em primeiro lugar, a política de estabilização econômica implementada a partir da adoção do Plano Real permitiu o controle das altas taxas de inflação verificadas nos anos 1980 e começo dos anos 1990. Aliado a isso, o progressivo crescimento da oferta de vagas no mercado de trabalho formal e uma política persistente de aumento do salário mínimo permitiu que parte dos extremamente pobres da população se apropriasse de uma parcela maior de renda (Flores 2017), ganhando condições de usufruir de bens e serviços, até então, fora do horizonte desses cidadãos (Neri 2011).

Entretanto, baixos níveis de inflação e crescimento econômico não teriam sido capazes de promover efeitos da magnitude observada não fosse a adoção de políticas específicas, voltadas para o combate da pobreza. O BPC é um típico caso de política social de Estado ${ }^{10}$, voltada ao combate da desigualdade de renda e da pobreza, e que teve seus efeitos potencializados por um conjunto de políticas econômicas e sociais adotadas em diferentes governos no Brasil.

No Gráfico 2, é possível visualizar as tendências de concentração de indivíduos extremamente pobres, entre 1992 e 2012. Foram considerados extremamente pobres os indivíduos com renda familiar mensal per capita inferior a 1/4 do salário mínimo. O salário mínimo do último ano para o qual a série está sendo calculada torna-se a referência para toda a série. Esse valor é corrigido para todos os anos anteriores com base no Índice Nacional de Preços ao Consumidor (INPC) de setembro do último ano, alterando o valor da linha de pobreza e, consequentemente, a proporção de pobres. Neste gráfico, o valor de referência, salário mínimo de 2012, é de R\$ 622. Os valores das PNAD 2001 a 2012 foram ponderados considerando os pesos amostrais disponibilizados após a publicação do Censo 2010.

Adotar uma linha de pobreza absoluta baseada na renda não significa ignorar que a pobreza deve ser considerada um fenômeno multidimensional baseado nas necessidades e capacidades dos indivíduos (Sen 1992; Anand \& Sen 1997), mas assumir que, para além do fato de ser necessário um critério dicotômico para diferenciar pobres de não pobres (Soares 2009), o critério de insuficiência de renda é razoável em países de "economia monetizada e de nível de renda média como o Brasil” (Rocha 2010, p.2). Outros critérios para a 


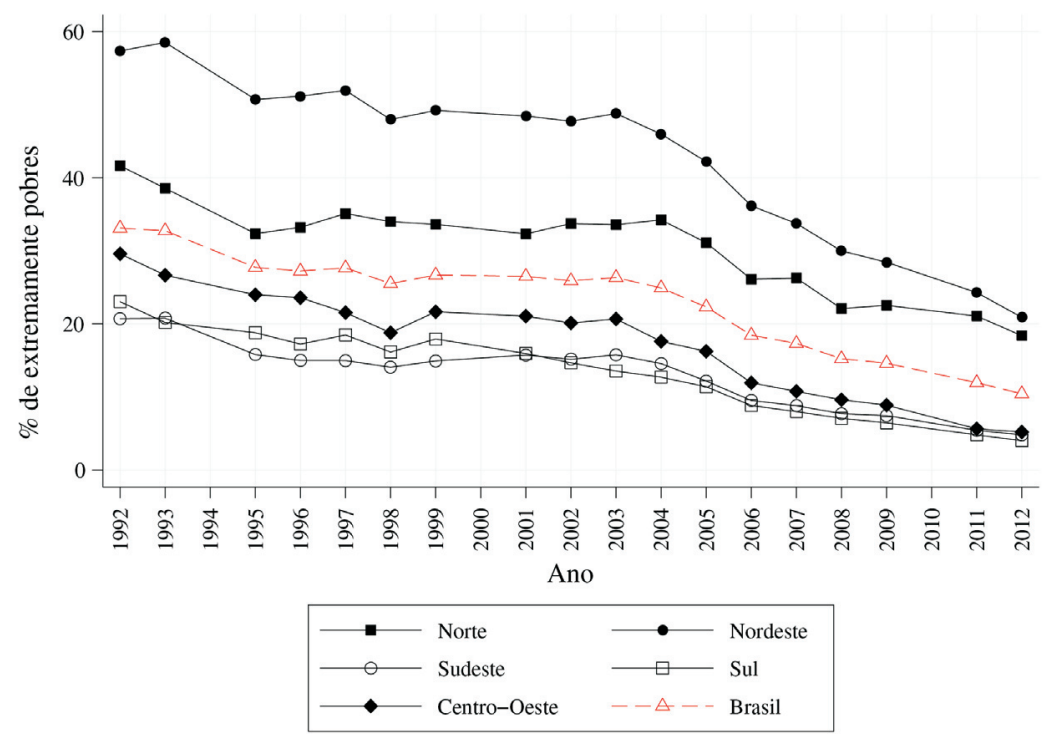

Fonte: Os autores, a partir da PNAD/DATASUS (2012).

${ }^{11}$ Critério utilizado para classificar os indivíduos extremamente pobres.

${ }^{12}$ Medidas administrativas de pobreza são aquelas informadas pelo Estado e utilizadas como parâmetro básico para a mensuração do fenômeno da pobreza. No caso brasileiro, a linha de corte de 1/4 do salário mínimo foi regulamentada pela Lei Orgânica de Assistência Social (LOAS), Artigos 21 e 22 da Lei ${ }^{\circ} 8.742,1993$.

${ }^{13}$ Neste caso, o salário mínimo deflacionado de cada ano.

\footnotetext{
${ }^{14}$ Benefício emitido é aquele que está (1) em situação ativa e (2) cujo valor foi efetivamente repassado ao beneficiário. Ao adotarmos a categoria "emitidos", garantimos que a variação
}

definição da linha de pobreza vêm sendo utilizados por especialistas. A linha de corte mais conhecida e utilizada no mundo é a medida de US\$ 1 per capita dia, elaborada pelo Banco Mundial e adotada pela Organização das Nações Unidas (ONU). Existe ainda o critério de corte utilizado no Brasil pelo programa Bolsa Família, cerca de $\mathrm{R} \$ 77$ per capita mensais ${ }^{11}$, e as linhas regionalizadas baseadas no consumo calórico, calculado por Rocha (2013) em cerca de R \$ 70, para o ano de 2011.

A opção por utilizar um critério de corte administrativo ${ }^{12}$ se dá por dois principais motivos. Primeiramente, ainda que o critério de renda signifique abordar a pobreza como um conceito absoluto, posto que o valor do BPC é atrelado ao valor do salário mínimo, a utilização de uma medida de pobreza derivada do seu valor permite comparar os ganhos dos beneficiários com a parcela dos trabalhadores que recebem a mesma renda média de referência ${ }^{13}$. Em segundo lugar, tendo em vista que o critério de entrada no programa é exatamente a linha de corte utilizada, torna-se possível deduzir, do montante de pobres em cada período do tempo, o número de novos beneficiários assistidos.

O Gráfico 2 permite concluir que, entre 1992 e 2012, a proporção de pobres caiu em todas as regiões do Brasil. Além disso, evidencia-se uma queda mais acentuada a partir dos anos 2000. Este é um reflexo das condições econômicas favoráveis, dos acréscimos em renda média e do efeito de um conjunto de políticas sociais que foram implementadas no período. Para os fins deste trabalho, interessa dimensionar a contribuição do BPC para essa tendência de queda. Para tanto, utilizamos dois métodos intuitivos. O primeiro deles segue representado no Gráfico 3.

Foi calculada a diferença absoluta do número de extremamente pobres $(X)$ e o número de benefícios emitidos ${ }^{14}$ do $\mathrm{BPC}\left(N_{B P C}\right)$ para um determinado ano $i$. Com os dados do número líquido de indivíduos que se tornaram beneficiários do BPC a cada ano $j_{i}$ foi possível simular um cenário contrafatual, ou seja, qual seria a proporção de pobres em cada região nos anos subsequentes caso o benefício não existisse. O Gráfico 3 apresenta, desse modo, o percentual anual acumulado de redução da pobreza em cada região por efeito estimado do BPC. 
anual mensurada capta apenas a diferença líquida do número de beneficiários, obtendo indicadores sem viés de superestimação. Em outras palavras, a utilização de benefícios emitidos garante que os resultados não estão sobre-estimados pela contagem de benefícios cessados ou suspensos.

15 O cálculo não foi realizado para os anos censitários. Como é sabido, a PNAD e o Censo utilizam metodologias diferentes para o cálculo das amostras, produzindo variações nas estimativas calculadas a partir dos dois levantamentos. Razão pela qual as duas fontes de informação não podem ser comparadas. As estimativas de pobreza utilizadas nos gráficos $2,3,4,5,6,8$ e 9 foram sistematizadas pelo DATASUS a partir das informação da PNAD.
A esta redução percentual denominamos "Negativo de Pobreza", cuja fórmula segue descrita abaixo:

$$
N P=\left(\left(\frac{X_{i}-N_{B P C_{i}}}{X_{i}}\right)-1\right) \times 100
$$

Algumas evidências merecem destaque. A primeira delas é o aumento do peso relativo dos negativos de pobreza no tempo. Entre 1996 e $2012^{15}$ existe uma tendência de aumento da taxa de decréscimo em todas as regiões. Na linha de pobreza que representa o Brasil, enquanto em 1996 a taxa de redução de pobreza foi de $-0,85 \%$, em 2012 , o percentual negativo foi de $-19,26 \%$. Isto está relacionado com o aumento do número de indivíduos retirados da condição de vulnerabilidade social. Há de se ressaltar também dois outros fatores: a mudança na composição da pirâmide etária brasileira e o efeito informacional sobre o número de novos beneficiários.

Dado que a expectativa de vida do brasileiro aumentou no último quarto de século (Nasri 2008) e as taxas de fecundidade declinaram (Carvalho 2004), a proporção de idosos vem aumentando ao longo do tempo. Isso não significa que todos sejam potenciais beneficiários, mas existe maior probabilidade de que pessoas cheguem aos 65 anos dependentes de auxílio do Estado para satisfazer suas necessidades básicas. No que se refere ao efeito informacional, mesmo sendo uma garantia constitucional, por muito tempo a existência do programa permaneceu encoberta para a maior parte da população. Razão pela qual a proporção de beneficiários sempre foi maior nas áreas urbanas, nos lugares onde os canais de informação são mais efetivos (Medeiros, Diniz \& Squinca 2006).

O Gráfico 3 informa também maiores taxas de negativos de pobreza nas regiões com menor proporção de pobres. A razão é simples e segue uma lógica aritmética: o efeito da redução do número de pobres em regiões com uma grande proporção de pobres é menor do que numa região com reduzida parcela de pobres. Uma alternativa para tornar mais evidente o efeito do BPC sobre as tendências regionais de pobreza é comparar visualmente as tendências de

Gráfico 3 - Negativos de pobreza por região (1996-2012)

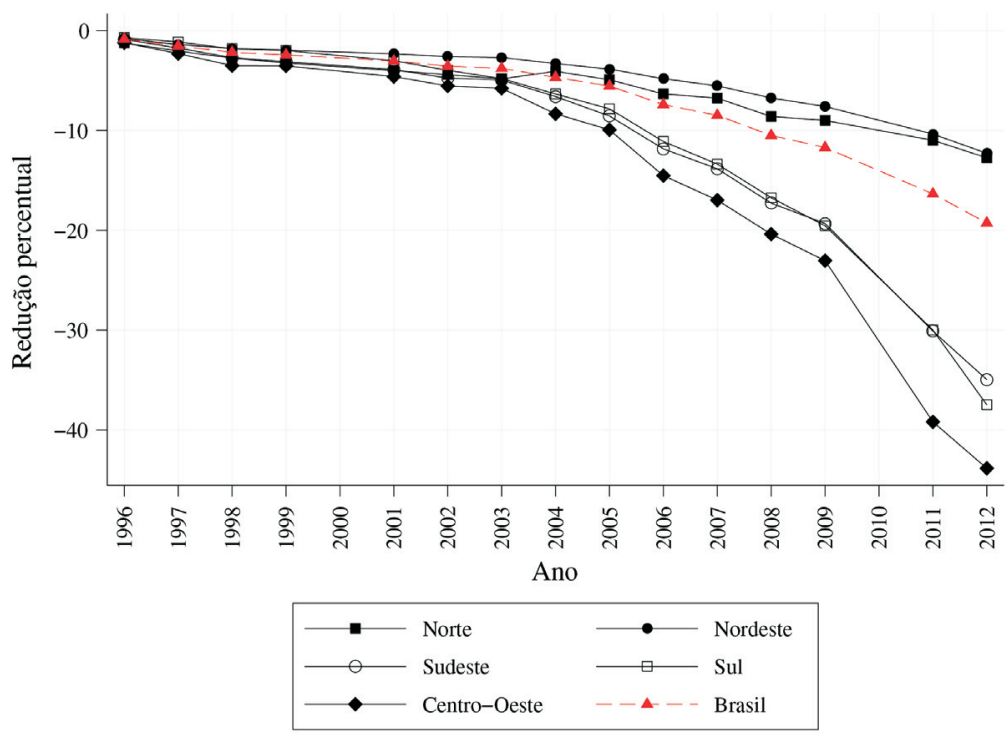

Fonte: Os autores, a partir da PNAD/DATASUS (2012). 
${ }^{16}$ Como a taxa de redução da pobreza varia entre as regiões, a distância entre as linhas de uma região não deve ser tomada como referências para outras regiões, mas para dimensionar o quanto da redução da população de extremamente pobres pode ser explicada pelo BPC, tendo como referência a própria região. pobreza simuladas - sem o efeito do BPC - e as tendências de pobreza observadas. A operacionalização deste exercício pode ser visualizada nos Gráficos 4 , 5 e 6 .

Nos três gráficos, as linhas do eixo [Y1] apresentam a variação, no tempo, da proporção de pobres. Se o BPC não tivesse nenhum efeito sobre a proporção de pobres de cada região, as duas linhas estariam completamente sobrepostas. Quanto maior a distância entre as duas linhas, maior é o feito do BPC sobre a taxa de pobreza regional ${ }^{16}$. Esta distância entre as linhas é determinada pela magnitude da redução da pobreza. A linha tracejada vermelha representada no eixo [Y2], por sua vez, apresenta as taxas de negativos de pobreza no tempo (efeito do BPC sobre a linha de pobreza regional).

No período analisado a região Sudeste e Sul reduziram, em média, 11,69\% e $11,36 \%$, ao ano, respectivamente, a proporção de pobres (Gráfico 4). As regiões Norte e Nordeste apresentaram menores valores médios de negativos de pobreza, 6,05\% e 4,81\%, respectivamente (Gráfico 5). Em outra direção, nenhuma região teve sua taxa de pobreza tão impactada pelo BPC como a região Centro-Oeste (Gráfico 6). Entre 1996 e 2012, a região apresentou uma taxa média de redução da pobreza de $14,39 \%$ ao ano. Estes dados vão ao encontro das evidências apresentadas por Manso, Barreto e Tebaldi (2006) e Resende, Da Mata e Carvalho (2007), que sugerem um maior efeito do aumento da renda média sobre a redução da pobreza nesta região, e da tendência observada por Azzoni (1997) de aumento do PIB per capita na região Centro-Oeste desde o início da década de 1990.

Gráfico 4 - Negativos de pobreza e tendências de extrema pobreza nas regiões Sul e Sudeste (1996-2012)
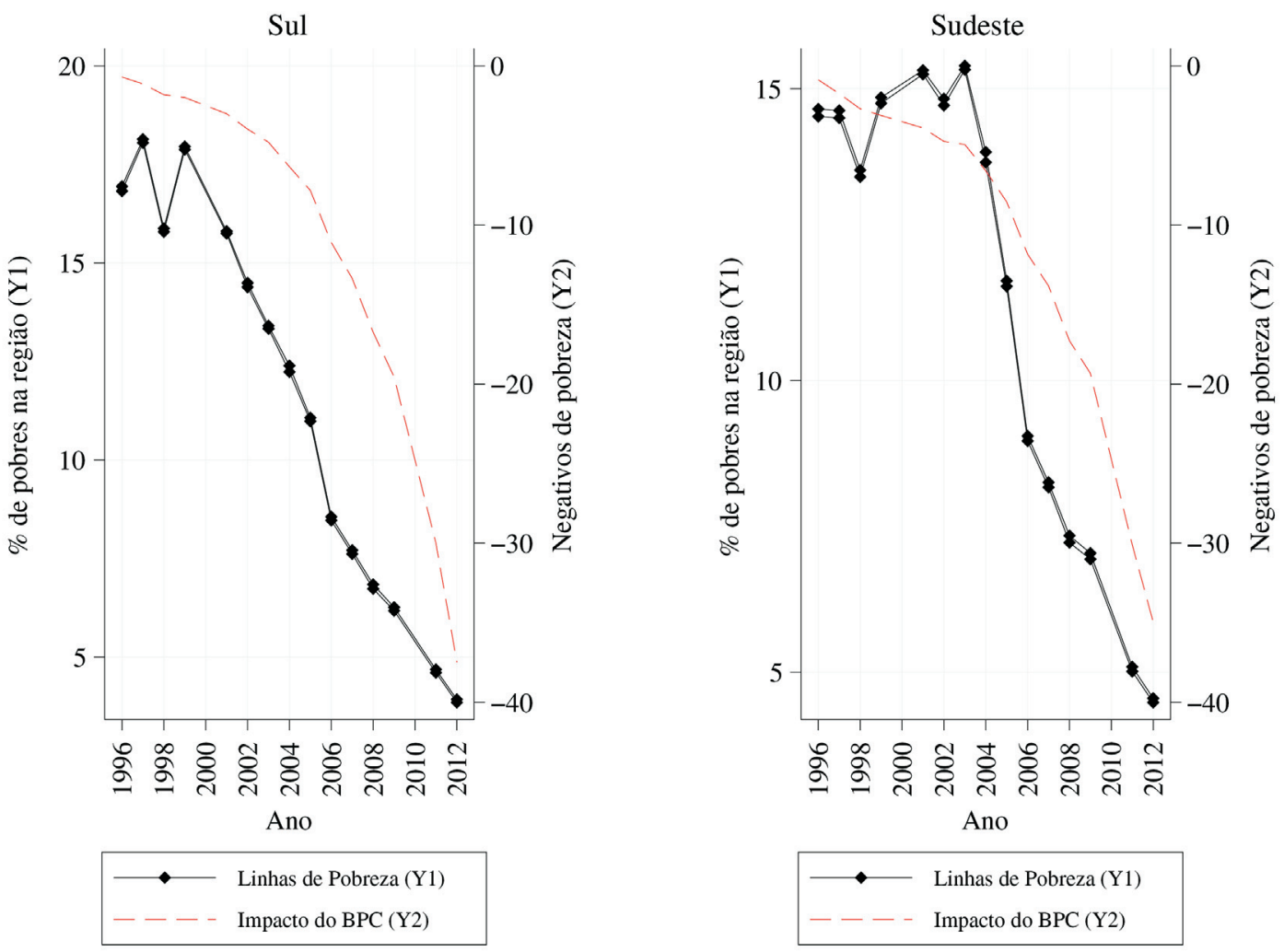

Fonte: Os autores, a partir da PNAD/DATASUS (2012) e Ministério do Desenvolvimento Social (2015). 
Gráfico 5 - Negativos de pobreza e tendências de extrema pobreza nas regiões Norte e Nordeste (1996-2012)
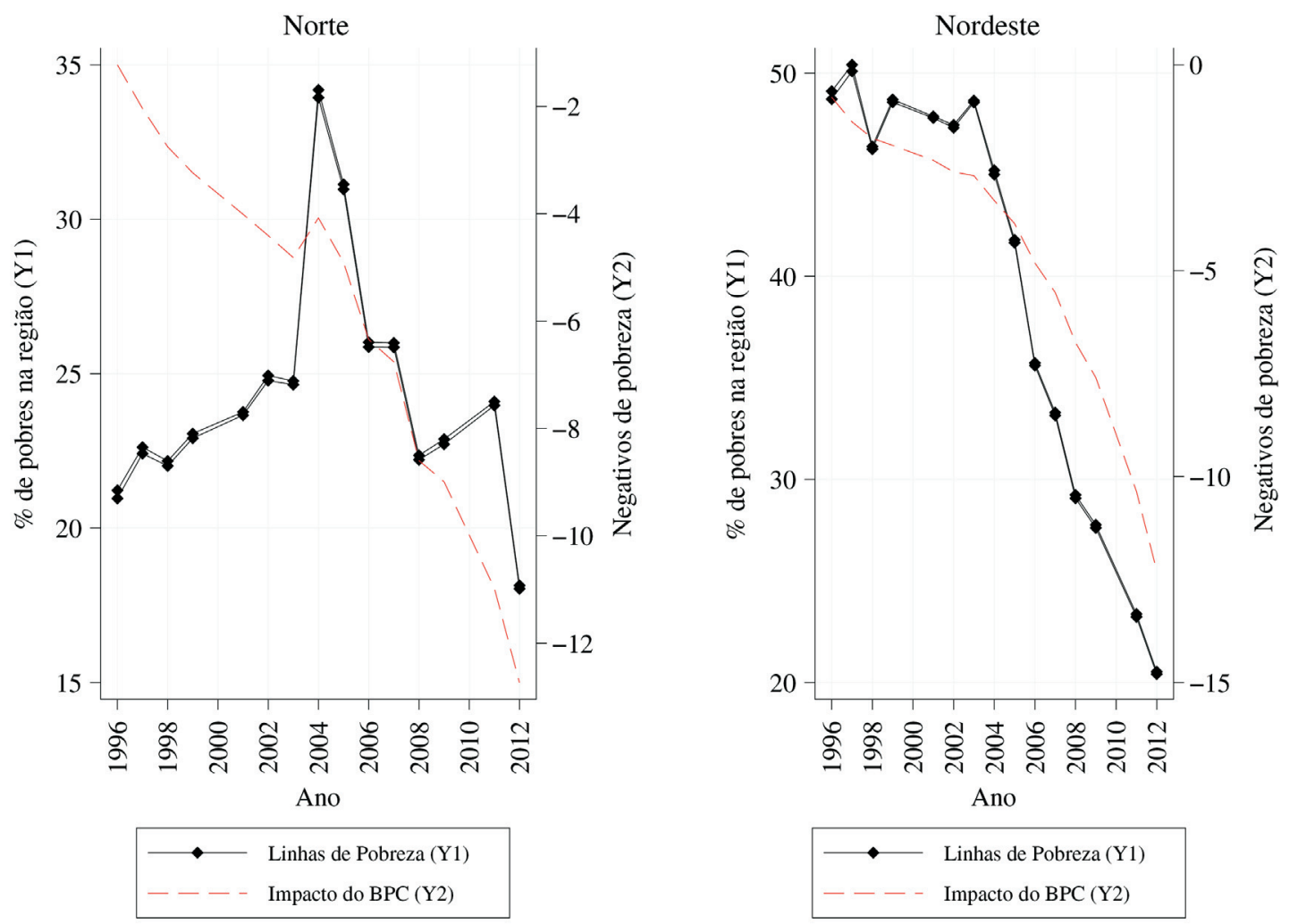

Fonte: Os autores, a partir da PNAD/DATASUS (2012) e Ministério do Desenvolvimento Social (2015).

A maior distância entre as linhas está associada ao aumento da cobertura do BPC. O crescimento dos gastos e a tendência observada no tempo de maior adesão ao benefício produziram efeitos evidentes sobre as tendências de pobreza regional no Brasil. Estes efeitos podem ser notados desde a década de 1990, mas se revelam de forma mais intensa a partir de meados dos anos 2000 (ver Gráfico 6).

A Tabela 1 reporta a contribuição de cada região para a proporção de extremamente pobres no Brasil entre 1996 e 2012. Nota-se que, em todos os anos analisados, o BPC contribuiu para a redução da proporção de pobres nas regiões do Brasil. Analisando apenas a diminuição relativa da pobreza, o efeito do BPC é pequeno. No entanto, em termos absolutos, a retração da pobreza em cada região representa a retirada de um número considerável de indivíduos da condição de extremamente pobres. Cerca de quatro milhões de indivíduos socialmente vulneráveis passaram a acessar uma renda mínima neste período. Este exercício ganha ainda mais amplitude quando comparamos a melhoria das condições de bem-estar dessa população acessada pelo BPC com os ganhos que eles teriam no tempo se estivessem integrados ao mercado de trabalho formal.

O fato de o BPC conceder aos seus beneficiários o valor de um salário mínimo, significa possibilitar a estes indivíduos em situação de vulnerabilidade social os mesmos ganhos em renda transferidos aos participantes do mercado de trabalho formal. Neste caso, a combinação entre uma política econômica e a característica desmercadorizante (Esping-Andersen 1985) de uma política social de Estado produzem um cenário favorável à redução da pobreza. 
Gráfico 6 - Negativos de pobreza e tendências de extrema pobreza na região Centro-Oeste e no Brasil (1996-2012)
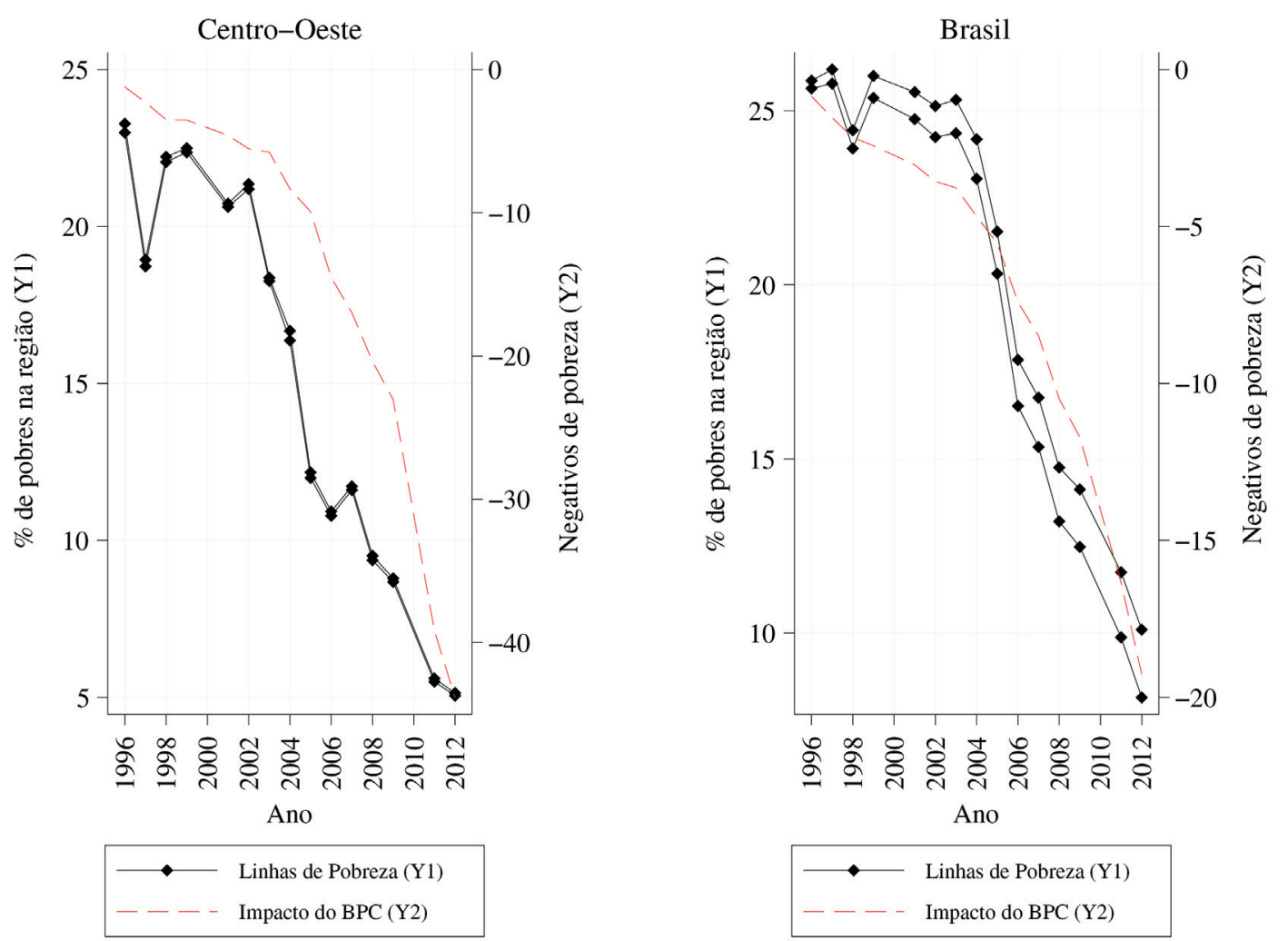

Fonte: Os autores, a partir da PNAD/DATASUS (2012) e Ministério do Desenvolvimento Social (2015).

Tabela 1 - Efeito do BPC sobre a contribuição de cada região à pobreza total no Brasil (1996-2012)

\begin{tabular}{|c|c|c|c|c|c|c|c|c|c|c|}
\hline & \multicolumn{2}{|r|}{$\mathbf{N}$} & \multicolumn{2}{|c|}{ NE } & \multicolumn{2}{|c|}{ SE } & \multicolumn{2}{|r|}{$\mathbf{S}$} & \multicolumn{2}{|r|}{$\mathrm{CO}$} \\
\hline & $\%$ & $\%$ - ЕВРC & $\%$ & $\%$ - ЕВPC & $\%$ & $\%$ - ЕBPC & $\%$ & $\%$ - ЕBPC & $\%$ & $\%$ - ЕВPC \\
\hline 1996 & 5,90 & 5,82 & 54,12 & 53,69 & 24,16 & 23,95 & 9,81 & 9,74 & 6,02 & 5,94 \\
\hline 1997 & 6,28 & 6,22 & 54,67 & 54,33 & 23,82 & 23,61 & 10,35 & 10,30 & 4,88 & 4,82 \\
\hline 1998 & 6,65 & 6,61 & 53,75 & 53,59 & 23,73 & 23,52 & 9,70 & 9,64 & 6,18 & 6,13 \\
\hline 1999 & 6,56 & 6,52 & 52,89 & 52,74 & 24,34 & 24,17 & 10,29 & 10,25 & 5,92 & 5,89 \\
\hline 2001 & 7,14 & 7,11 & 52,56 & 52,47 & 25,57 & 25,46 & 9,13 & 9,10 & 5,59 & 5,57 \\
\hline 2002 & 7,67 & 7,62 & 52,80 & 52,65 & 25,15 & 24,95 & 8,49 & 8,43 & 5,89 & 5,84 \\
\hline 2003 & 7,62 & 7,59 & 53,62 & 53,52 & 25,91 & 25,80 & 7,79 & 7,75 & 5,05 & 5,02 \\
\hline 2004 & 11,19 & 11,11 & 51,93 & 51,69 & 24,52 & 24,20 & 7,52 & 7,42 & 4,85 & 4,76 \\
\hline 2005 & 11,54 & 11,48 & 53,77 & 53,59 & 23,17 & 22,98 & 7,53 & 7,47 & 4,00 & 3,94 \\
\hline 2006 & 11,72 & 11,66 & 55,32 & 55,13 & 21,59 & 21,39 & 7,01 & 6,93 & 4,35 & 4,29 \\
\hline 2007 & 12,57 & 12,50 & 54,75 & 54,53 & 20,97 & 20,76 & 6,71 & 6,63 & 4,99 & 4,94 \\
\hline 2008 & 12,10 & 12,02 & 55,48 & 55,17 & 21,04 & 20,70 & 6,72 & 6,61 & 4,66 & 4,59 \\
\hline 2009 & 12,99 & 12,90 & 55,02 & 54,71 & 21,06 & 20,75 & 6,41 & 6,32 & 4,52 & 4,46 \\
\hline 2011 & 17,17 & 17,08 & 55,34 & 55,01 & 18,25 & 17,97 & 5,71 & 5,62 & 3,53 & 3,47 \\
\hline 2012 & 15,15 & 15,06 & 56,55 & 56,21 & 18,97 & 18,67 & 5,55 & 5,45 & 3,79 & 3,72 \\
\hline
\end{tabular}

Fonte: Os autores, a partir da PNAD/DATASUS (2012) e Ministério do Desenvolvimento Social (2015). 
${ }^{17} \mathrm{O}$ valor de $\mathrm{R} \$ 788$ é referente a 2015.

${ }^{18}$ De acordo com os dados do Dieese, em 1995, o valor de um salário mínimo era suficiente para garantir a compra de uma cesta básica. Em janeiro de 2015, no último ano da séria analisada, era possível comprar pouco mais de duas cestas básicas com um salário mínimo.
Como pode ser visualizado no Gráfico 7, existe uma tendência de aumento real do salário mínimo pelo menos desde 1994, após período com forte tendência de desvalorização. Embora só em 2015 o salário mínimo tenha alcançado o valor real que tinha em 1983,foi apenas a partir da estabilização econômica, alcançada por meio do Plano Real, que o salário mínimo passou por um processo de contínua valorização, mais do que dobrando de valor entre 1995 e 2015. A tendência de aumento do período anterior (1983-1994) está associado à alta inflação, no qual o governo realizava sucessivos reajustes do salário mínimo em um mesmo ano com o objetivo de preservar minimamente seu poder de compra sem pressionar ainda mais a inflação via aumento do consumo. O sucesso do plano de estabilização da economia brasileira colocado em prática no governo Itamar Franco (1992-1994), e a política de valorização do salário mínimo (SM) iniciada no governo Fernando Henrique Cardoso (1995-2002) e continuada nos governos Luís Inácio da Silva (2003-2010) e Dilma Rousseff (2011-2014) são os principais determinantes deste aumento real e linear. O cenário de recuperação contínuo permitiu que, em 2015, o SM alcançasse o maior valor ${ }^{17}$ na série desde 1983.

Como mostram Saboia (2007; 2014) e Summa (2015), o aumento do salário mínimo contribuiu para o aumento dos rendimentos de trabalho da parcela inferior da distribuição de renda. Estes resultados corroboram estimativas anteriormente reportadas pela literatura e que demonstraram o mesmo efeito positivo do SM na distribuição de renda (Fajnzylber 2001; Lemos 2001; Soares 2002). Importa destacar que os ganhos em renda possibilitados pela tendência de aumento real do SM contribuíram para o aumento da capacidade de atendimento das necessidades nutricionais básicas daqueles em condições de acessar o mercado de trabalho ${ }^{18}$.

Isso não significa que a satisfação de todas as suas necessidades esteja garantida a estes indivíduos (Sen 1997), nem que eles estejam permanentemente livres da condição de vulnerabilidade, mas sinaliza a melhora da qualidade de vida de indivíduos anteriormente em condições de indigência.

Gráfico 7 - Salário Mínimo Real Médio, Brasil (1983-2015)

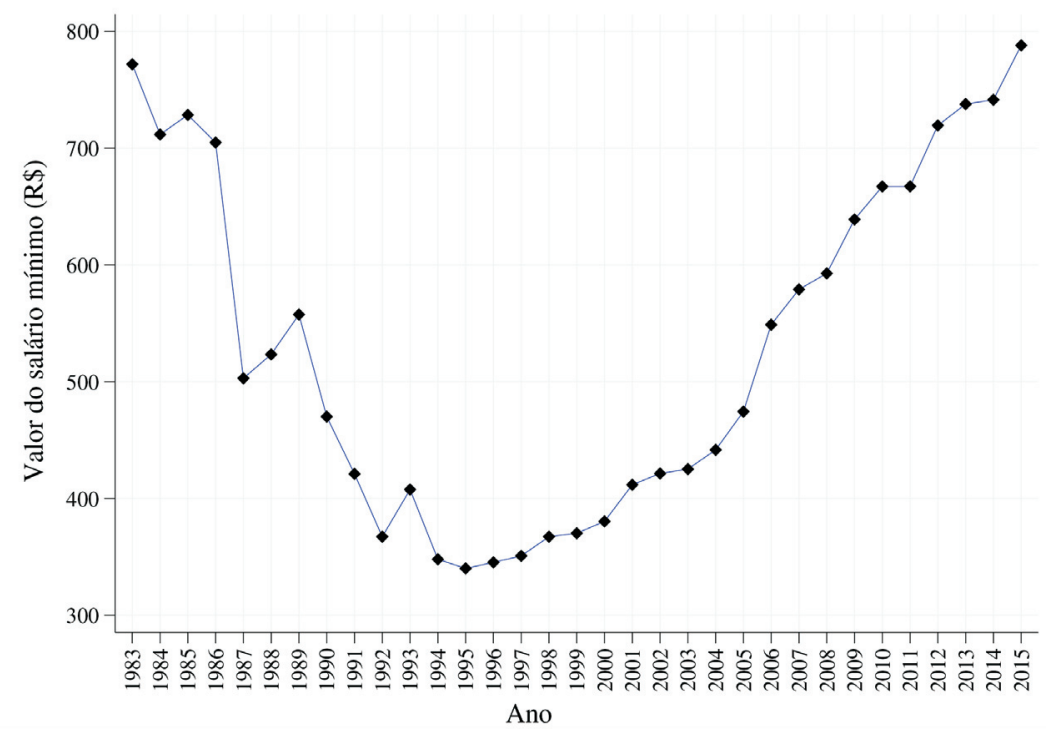

Fonte: Os autores, a partir do DIEESE (2015).

Nota: Valores médios anuais para reais de $1^{\circ}$ de janeiro de 2015 , deflacionados por projeção a partir do Índice de Custo de Vida (DIEESE). 
A questão que se coloca, no entanto, é em que medida a redistribuição no nível interpessoal promovida pelo BPC, uma política em que arrecadação e os gastos são centralizados no governo central, implica redistribuição automática de recursos entre os territórios. Em outros termos, a transferência de renda para indivíduos viabilizada pelo benefício permitiu que a distância entre as regiões mais pobres e as regiões mais ricas diminuísse?

\section{Redistribuição de renda no nível interpessoal e os seus efeitos sobre a desigualdade territorial no Brasil}

${ }^{19}$ Uma síntese das ideias formuladas por Celso Furtado para repensar a questão da integração nacional no Brasil pode ser consultada em Furtado (1959). Para uma discussão da obra deste autor ver Cano (2000) e Bacelar (2000).
${ }^{20}$ A região de referência é a região com menor proporção de pobres em cada ano analisado. Nos anos de 1992, 1995, 1996, 1997, 1998, 1999 e 2001, a região de referência foi a Sudeste. Nos demais anos da série a região de referência foi a Sul.
${ }^{21}$ Os coeficientes de concentração foram gerados a partir da comparação do
A questão da desigualdade territorial no Brasil é um problema antigo e de natureza persistente (Azzoni 2001; Vainer 2007 Soares et al., 2015; Mesquita et al., 2015). Desde os esforços sistemáticos realizados por Celso Furtado na tentativa de pensar ações que pudessem integrar as regiões Norte e Nordeste ao projeto de desenvolvimento nacional ${ }^{19}$, o conjunto de políticas implementadas com o objetivo de sanar esta questão não logrou sucesso (Ferreira 2004).

Alguns analistas sugerem que o aumento médio das rendas provocado pelo crescimento econômico recente colaborou para uma tendência de redução das disparidades regionais no Brasil. Como determinantes dessa tendência, são apontadas tanto as políticas ligadas ao mercado de trabalho (Hoffmann 2006) quanto as políticas de caráter não contributivo (Silveira-Neto \& Azzoni 2012). No último caso, quando a variação do PIB per capita das regiões é a dimensão a ser explicada, o Benefício de Prestação Continuada é apontado como fator relacionado ao processo de redução das desigualdades regionais.

Quando a dimensão da pobreza é considerada como variável-chave, os resultados apontam em outra direção. A análise empreendida por Rocha (1998) indica um agravamento da tendência de concentração da pobreza nas regiões mais pobres. Os trabalhos mais recentes sugerem que, embora haja uma tendência de diminuição da pobreza por efeito do aumento das rendas médias, essa diminuição se dá de forma descontínua (Manso, Barreto \& Tebaldi 2006; Resende, Da Mata \& Carvalho 2007).

$\mathrm{Na}$ seção anterior, mostramos o impacto do BPC sobre as tendências regionais de pobreza. Por efeito do BPC, que garante transferência interpessoal de renda, uma parcela significativa de indivíduos em todas as regiões foi retirada da condição de extrema pobreza entre 1996 e 2012. Importa saber, contudo, se o impacto do benefício sobre a pobreza implica fluxos redistributivos automáticos entre os territórios. No Gráfico 8, apresentamos as razões de pobreza entre as regiões com maior proporção de pobres e a região de referência ${ }^{20}$ com menor proporção de pobres.

Com exceção da região Centro-Oeste que apresenta tendência de estabilidade na série, as demais regiões (Norte e Nordeste) se distanciaram dos territórios com menor concentração de pobreza. Em 1992, a região Nordeste tinha três vezes mais indivíduos pobres que a região menos pobre de referência. No ano de 2012, a razão verificada é de mais de cinco vezes a quantidade de pobres da região menos pobre de referência. No caso da região Norte, nos mesmos pontos da série, a razão era de duas vezes em 1992 e mais de quatro vezes e meia em 2012. Estes resultados indicam que, a despeito da redução da concentração de pobres em todo o território brasileiro, existe uma tendência no tempo de distanciamento entre as regiões. Ou seja, junto com a suavização das tendências de pobreza regional tem ocorrido o agravamento da desigualdade territorial.

No Gráfico 9 [A], pode ser visualizada a taxa de concentração de pobreza medida pelo Coeficiente de Gini ${ }^{21}$. As regiões do Brasil foram comparadas com o objetivo de mensurar qual o grau de desigualdade entre elas. A linha tracejada diz respeito à concentração de extremamente pobres considerando o efeito do 
percentual de indivíduos extremamente pobres das regiões, em cada ano analisado.
Gráfico 8 - Razão entre as regiões com maior concentração de pobreza e a região de referência com menor concentração de pobreza (1992-2012)

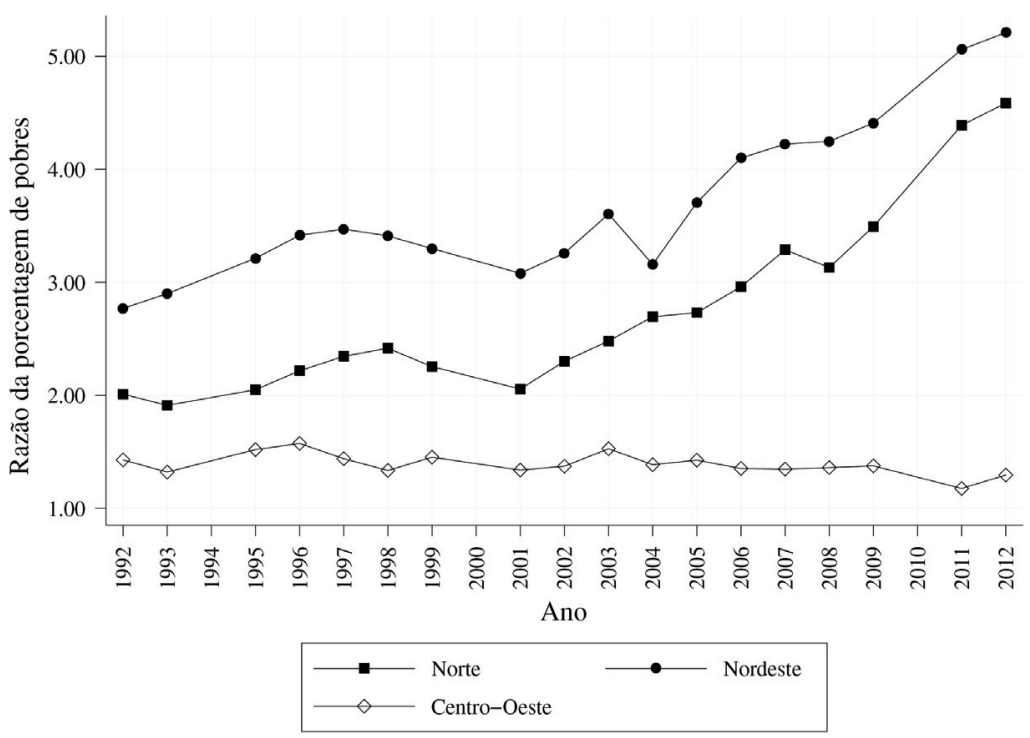

Fonte: Os autores, a partir da PNAD/DATASUS (2012).

Nota: As razões foram calculadas levando em consideração todos os indivíduos com renda per capita familiar mensal inferior a 1/4 do salário mínimo.

BPC sobre as tendências de pobreza regional. A intenção é verificar se, ao impactar mais a redução da pobreza nas regiões com menor concentração de pobres, o BPC colabora para o aumento da desigualdade entre os territórios.

Os resultados apresentados no Gráfico 9 [A] evidenciam dois padrões distintos na série analisada. No primeiro, que vai de 1996 até 2003, a transferência de renda interpessoal ensejada pelo benefício colabora para a redução da desigualdade territorial (ver linha tracejada vermelha). Neste período, o benefício apresenta efeito sobre a redução da taxa de concentração de pobreza (ver linha vermelha tracejada).

O segundo padrão, que teve início em 2004 e se estende até 2012, revela uma tendência oposta. A linha calculada considerando o efeito do BPC apresenta valores mais altos do Gini. Isso indica que, a partir de 2004, o benefício começa a contribuir para a desigualdade territorial no Brasil. Quando o benefício foi implantado, em 1996, a região Nordeste tinha um número de beneficiários significativamente maior que as outras regiões. Esta diferença ajudava a compensar as outras dimensões relacionadas à pobreza que determinam sua condição de território mais pobre.

O Gráfico 9 [B] apresenta, entre 1996 e 2012, a diferença entre o percentual de beneficiários nas regiões Nordeste e Sudeste. O BPC contribuiu para a diminuição ou para a estabilidade da desigualdade territorial até o ano de 2003, quando a diferença entre as duas regiões foi igual ou superior a cinco pontos percentuais. A partir desse patamar, o benefício passa a contribuir para o aumento da desigualdade entre as regiões. Quando as duas regiões passam a registrar um número similar de beneficiários, dadas as outras dimensões que estão relacionadas à pobreza e que pesam contra a região Nordeste, o efeito do BPC se torna positivo (observa-se o aumento da desigualdade entre os territórios). 
Gráfico 9 - Impacto do BPC sobre o coeficiente de concentração de Pobreza [A] e diferença percentual entre as duas regiões com mais beneficiários [B]
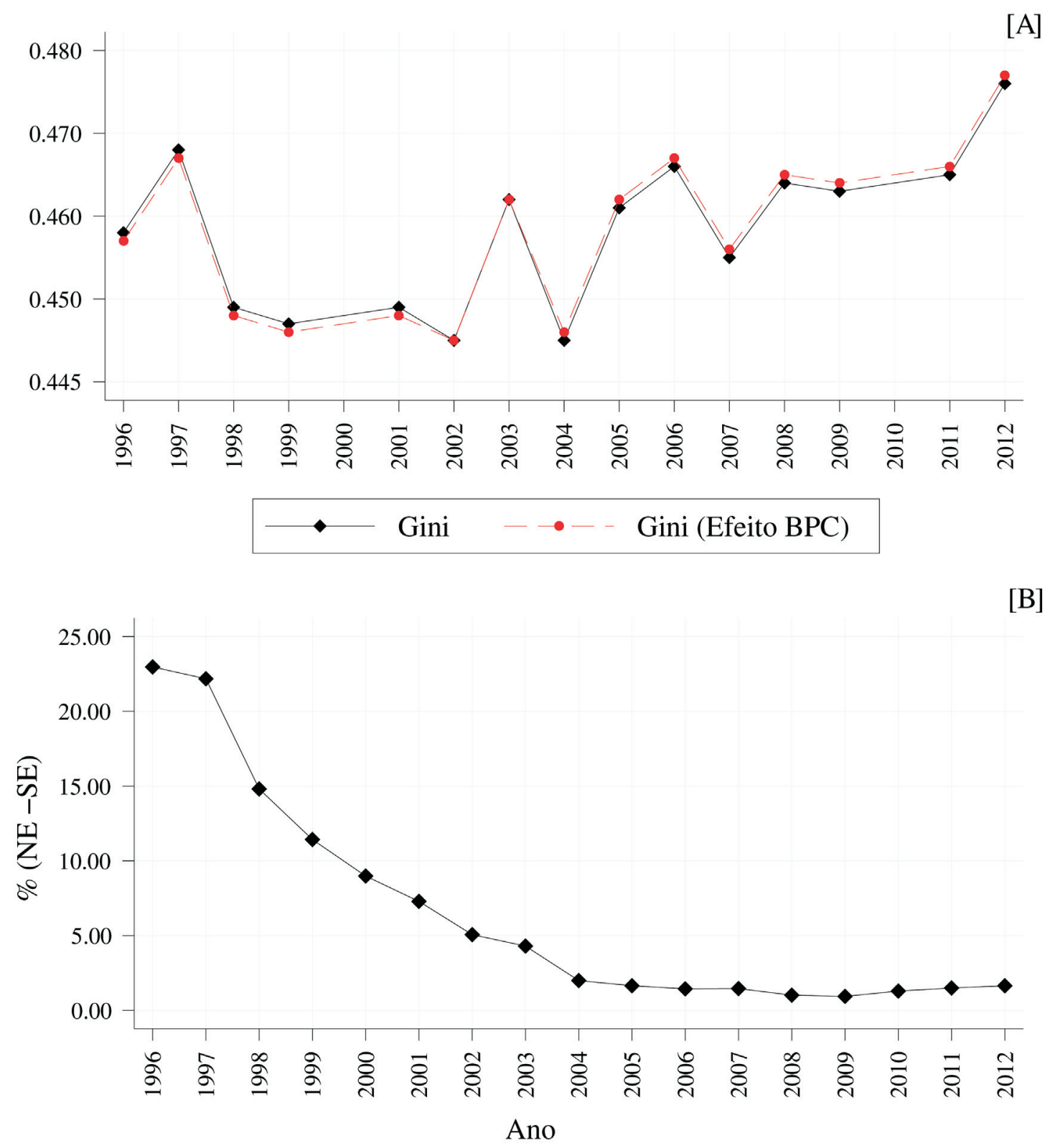

Fonte: Os autores, a partir da PNAD/DATASUS (2012) e Ministério do Desenvolvimento Social (2015).

Em 1996, a região Nordeste registrava 87.430 benefícios ativos a mais do que a região Sudeste, ao passo que em 2012 a mesma diferença era de 62.013. Entretanto, tais unidades representavam uma distância proporcional de $101 \%$, em 1996, e apenas 4,3\% em 2012. Isso se deve à expansão do número total de beneficiários. Uma vez que o quadro inicial de pobreza difere de região para região, bem como os fatores econômicos e sociais que afetam simultaneamente a persistência do fenômeno, a expansão da cobertura de uma política redistributiva nacional favorece resultados positivos mais expressivos nas regiões em que a pobreza sofre menos resistência de outros fatores. 
Diante dos distintos padrões observados, cabe discutir com mais atenção quais efeitos deveríamos esperar de uma política redistributiva de nível interpessoal sobre a desigualdade territorial. Em tese, o impacto seria nulo caso as distribuições esperada e observada de (1) cidadãos elegíveis nos territórios e (2) benefícios ativos por região fossem exatamente iguais e os demais fatores que afetam a dimensão da pobreza se mantivessem constantes ao longo de todo o período. A questão é que tal cenário é pouco factível e particularmente problemático em fenômenos multidimensionais como a pobreza. Sem a concretização desse cenário hipotético, fatores que afetem desigualmente o acesso dos cidadãos à política social ou que potencializem a concentração de beneficiários produzirão, necessariamente, variação nas taxas de concentração de pobreza observadas.

Ao desenharem políticas públicas, atores políticos buscam antecipar cenários prováveis e introduzem mecanismos que protegem a política de determinados choques externos que possam limitar o alcance de seus objetivos. No entanto, políticas redistributivas de caráter estritamente interpessoal, mesmo aquelas em que a alocação do gasto é centralizada pela União, são incapazes de resolver o problema da desigualdade entre regiões. Primeiramente, porque não são desenhadas para cumprir tal objetivo. Em segundo lugar, mesmo que os policy makers possam desejar que este seja um resultado indireto, fatores exógenos podem produzir consequências inesperadas e adversas.

O Gráfico 10 reporta o número absoluto de beneficiários, por região e grupo assistido. Nota-se uma tendência de crescimento de todas as regiões, nos dois grupos de beneficiários, ainda que esse crescimento seja substantivamente maior no Nordeste e Sudeste - as duas regiões mais populosas. Embora não seja a maior região em número de habitantes, devido ao maior número de indivíduos em condição de vulnerabilidade social, o Nordeste concentra o maior número de beneficiários.

Importa, para os objetivos deste trabalho, destacar as distintas tendências de crescimento dos grupos assistidos. Enquanto, no grupo dos deficientes, obser-

Gráfico 10 - Número de beneficiários do BPC por grupo assistido e região (1996-2012)

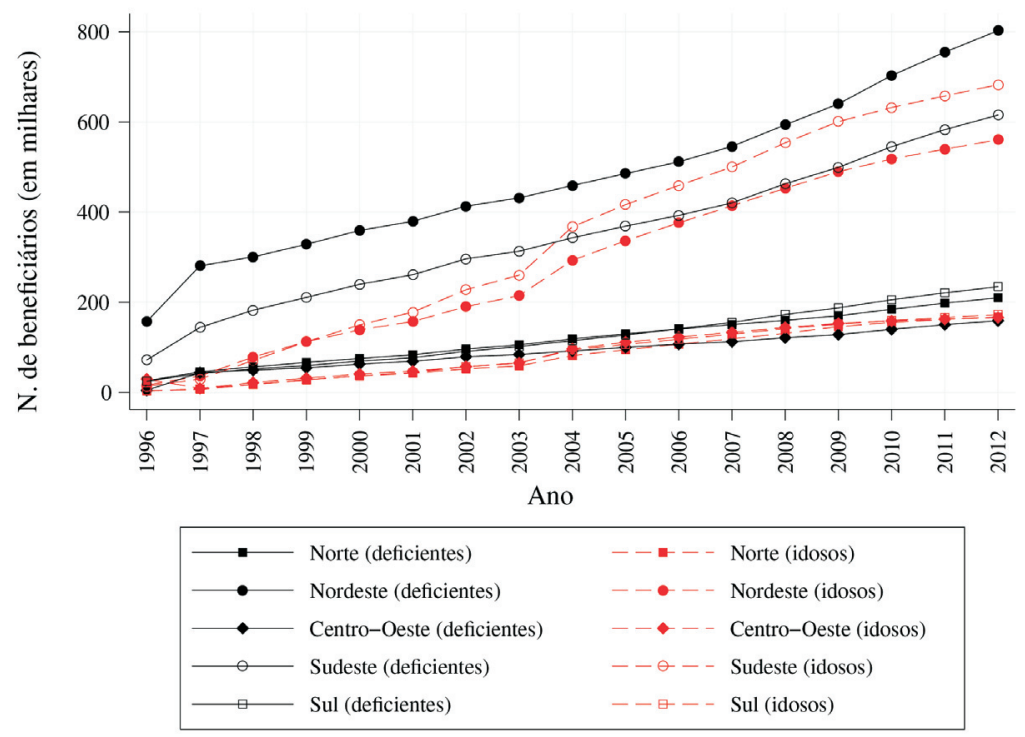

Fonte: Os autores, a partir das informações do Ministério do Desenvolvimento Social (2015). 
${ }^{22}$ Instituto Brasileiro de Geografia e Estatística (IBGE). Censos demográficos de 1940, 1950, 1960, 1970 e 2000.

${ }^{23}$ Ao contrário do que se especula normalmente, $o$ processo de envelhecimento populacional é uma consequência direta do declínio da fecundidade, não da queda da mortalidade.

${ }^{24}$ Proporção de idosos (60 anos ou mais de idade) que residem em domicílios como outro parente ou como agregado, ou seja, não chefiam, nem são cônjuges do chefe do domicílio em que residem. vamos uma variação paralela das linhas que representam as regiões, no grupo dos idosos, a partir do início da década dos anos 2000, é possível observar um descolamento das linhas que representam as duas regiões. Este descolamento é uma consequência direta do aumento do estoque de indivíduos idosos na região Sudeste. O grupo etário composto por pessoas de mais de 65 anos passou de $3,5 \%$, em 1970, para 5,5\% em 2000²2. Além disso, existem evidências de que a transição demográfica ocorre de forma desigual. Em outras palavras, o declínio da fecundidade ${ }^{23}$ nas regiões Sudeste e Sul revela-se historicamente maior (Wong \& Carvalho 2006). Como resultado, dado que o rápido declínio da fecundidade leva, necessariamente, a uma menor proporção de jovens e a uma maior proporção de idosos (Brito 2007), a população potencialmente elegível ao BPC cresceu num ritmo muito mais acelerado na região Sudeste.

É bem verdade que apenas o crescimento do número de idosos não implica maior número de indivíduos vulneráveis com idade igual ou superior a 65 anos. Entretanto, verificam-se também escalas diferentes de crescimento do número de idosos potencialmente vulneráveis entre as regiões. Como pode ser visualizado no Gráfico 11, entre 1996 e 2012, o número de idosos residentes em domicílio na condição de outro parente ${ }^{24}$ - aqueles idosos com maior propensão ao risco de vulnerabilidade social - cresceu mais acentuadamente na região Sudeste.

Mesmo que esta não seja uma medida direta de vulnerabilidade, a literatura vem demonstrando que idosos com maior renda e escolaridade são menos propensos a morar com seus filhos, parentes e/ou terceiros (Avery, Speare \& Lawton 1989; Cameron 2000; Bongaarts \& Zimmer 2002; Camargos, Machado \& Rodrigues 2006), e que maiores de 65 anos que não são chefes de família e residem com parentes são, via de regra, socialmente mais vulneráveis (Kinsella \& Velkolf 2001). Ademais, no caso brasileiro, os cuidados aos idosos vulneráveis são prestados predominantemente por suas famílias (Aquino \& Cabral 2002), sendo a co-residência um importante mecanismo de transferências intrafamiliares de apoio (Saad 2004).

Gráfico 11 - Número de idosos residentes em domicílios na condição de outro parente (1996-2012)

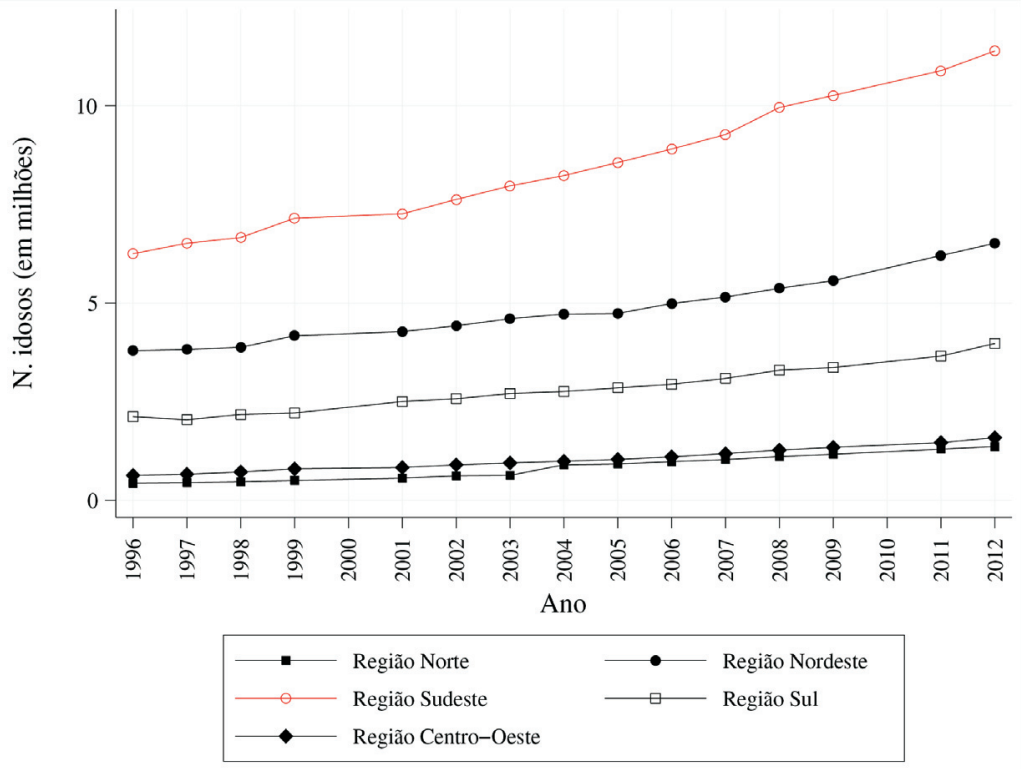

Fonte: Os autores, a partir da PNAD/DATASUS (2012). 
A inversão da tendência de concentração de pobreza observada no Gráfico 9 [A] teria ocorrido apenas por efeito deste fenômeno demográfico, ainda que numa velocidade menor. Todavia, a mudança na regra de acesso ao benefício, ensejada pelo Estatuto do Idoso, catalisou este processo.

Aprovado em outubro de 2003, o Estatuto do Idoso alterou a idade mínima para requerer o BPC, passando de 67 para 65 anos, ampliando significativamente o contingente de indivíduos aptos a acessar o benefício em todo o território nacional. Como podemos observar no Gráfico 12 [A], a alteração do critério para os idosos levou claramente ao aumento na concessão de benefícios para esse grupo em 2004, com retorno a índices menos intensos nos anos

Gráfico 12 - Taxa de crescimento do BPC para idosos [A] e deficientes [B], por região (1997-2012)

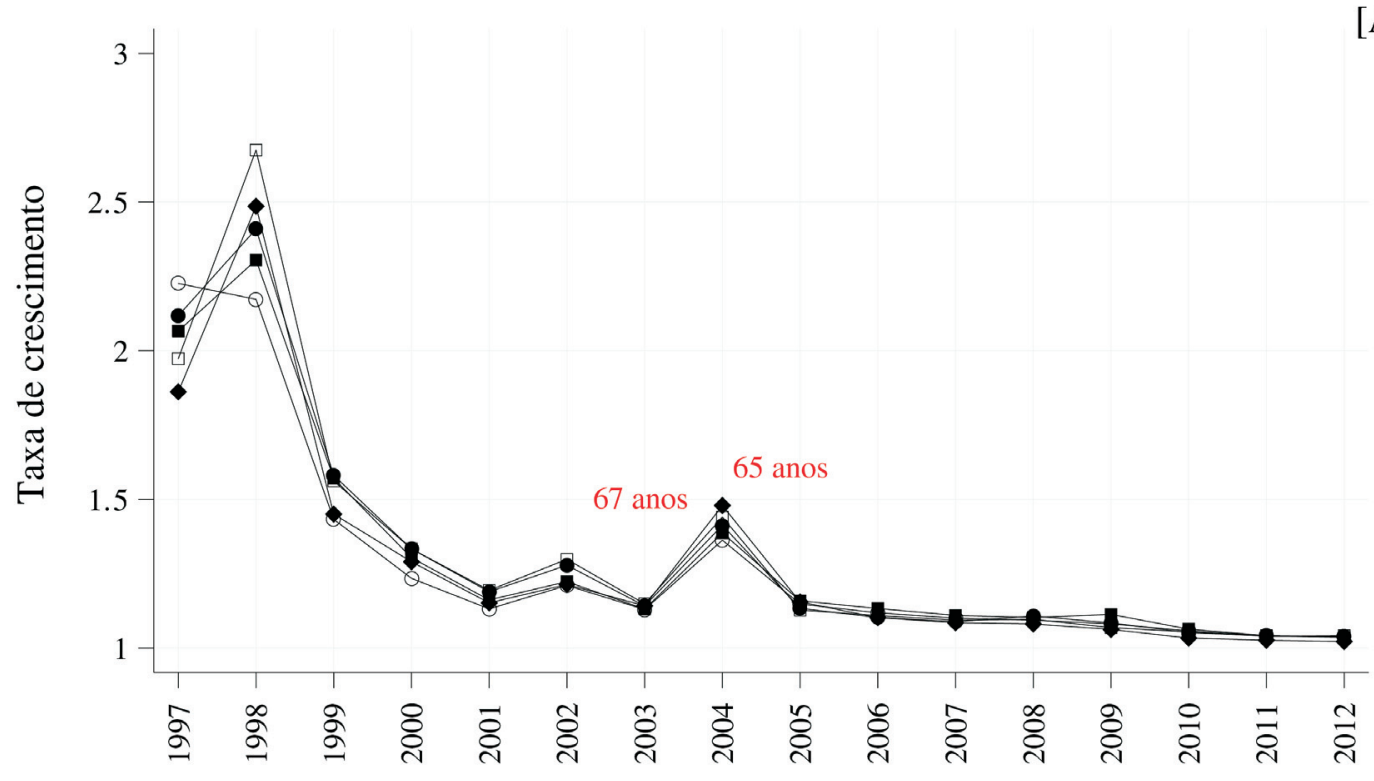

[A]

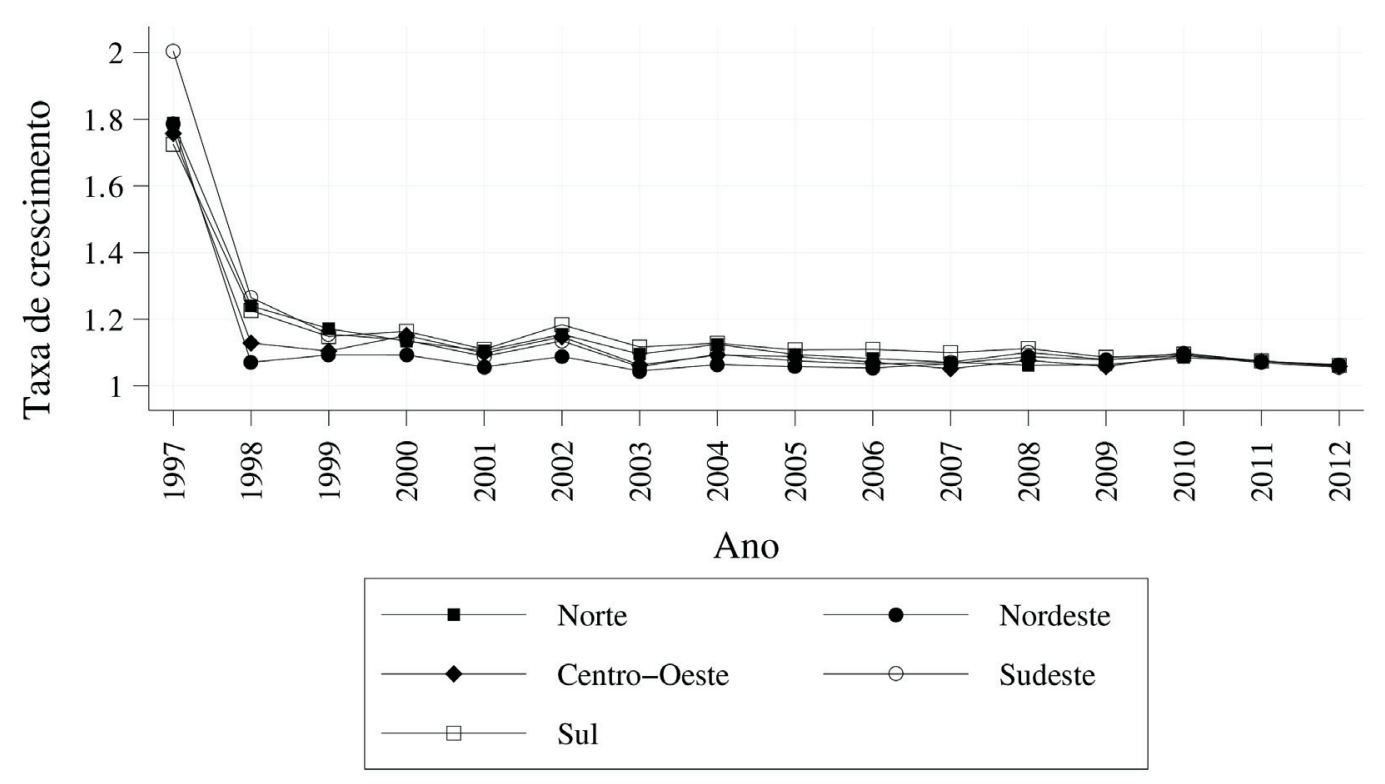

Fonte: Os autores, a partir das informações do Ministério do Desenvolvimento Social (2015). 
${ }^{25}$ A distância entre as das regiões é praticamente a mesma em todo o período analisado (1996-2012). posteriores - quando o efeito imediato de mudança da regra perdeu força. As evidências apresentadas no Gráfico 10 mostram como o número absoluto de beneficiários idosos no Nordeste e Sudeste sofreu forte aumento em 2004. No caso do Sudeste, a evolução foi significativa ao ponto do grupo de idosos dessa região tornar-se o segundo mais expressivo em números absolutos, atrás apenas de beneficiários deficientes na região Nordeste.

Assim, apesar de ter provocado aumento no número de idosos beneficiários em todas as regiões, a mudança da regra gerou impactos desiguais entre elas, intensificando o efeito da tendência demográfica de longo prazo. É dizer que, ao diminuir a idade mínima de acesso ao BPC, contribui-se para a tendência de concentração de benefícios em regiões cuja evolução numérica do estoque de idosos era mais expressiva. Por conseguinte, ao longo do tempo, a combinação destes dois fatores vem reduzindo a diferença percentual (da proporção de indivíduos assistidos) entre as duas regiões com mais beneficiários que ajudava a compensar a maior concentração de pobres no Nordeste.

O fato de não podermos precisar o número de indivíduos idosos que passaram a acessar o benefício em virtude da mudança na regra de elegibilidade poderia levantar dúvidas sobre o impacto do estoque desigual de indivíduos idosos e vulneráveis sobre a concentração de pobreza observada. Entretanto, a descontinuidade na taxa de crescimento do benefício ocorreu apenas neste grupo. Além de observarmos, nas regiões Nordeste e Sudeste, o crescimento paralelo $^{25}$ do número de beneficiários deficientes desde a implementação do BPC (ver Gráfico 10), a taxa de crescimento deste grupo se manteve estável em toda a série analisada (ver Gráfico 12 [B]). Estes são fortes indícios de que a concentração desigual de beneficiários nas regiões é resultante apenas da maior taxa de crescimento de estoque de idosos nas regiões mais ricas, sobretudo a região Sudeste.

Temos, portanto, que, para que a redistribuição de renda no nível interpessoal acarrete redistribuição automática de recursos entre regiões, é preciso assumir a premissa irreal de que todos os outros potenciais fatores que incidem sobre a pobreza permanecem estáveis no tempo. Nem mesmo a centralização do gasto de uma dada política social é capaz de garantir seu efeito redistributivo entre regiões, uma vez que fatores exógenos podem impedir que estes fluxos redistributivos sigam a distribuição da necessidade no território.

\section{Conclusões}

A trajetória recente de redução da pobreza no Brasil se confunde com o reestabelecimento da democracia e a institucionalização dos seus parâmetros na constituição de 1988. O pacote de medidas de assistência social incluídas na Carta Magna de 1988, para além dos avanços relacionados aos direitos humanos e sociais, lançou as bases de uma trajetória de desenvolvimento social.

Este fato não permite, contudo, negar a importância das decisões políticas que foram tomadas desde então. As decisões sobre policy que se sucederam fomentaram não apenas o controle da inflação e o crescimento econômico, mas um conjunto de medidas focalizadas com o intuito de diminuir a pobreza e a desigualdade de renda. Como foi argumentado neste trabalho, parte importante da redução da pobreza no Brasil pode ser explicada pelo efeito do Benefício de Prestação Continuada (BPC) sobre as tendências de pobreza regional.

Entretanto, a redução da concentração de indivíduos pobres nas regiões não tem se traduzido na diminuição das distâncias entre os territórios. Diferente do que preconiza a literatura estabelecida, nossos resultados indicam que o estabelecimento de uma política de transferência de renda em que a arrecadação e o gasto são centralizados na União é insuficiente para atenuar os níveis da 
desigualdade territorial. Ao contrário, fatores exógenos à estrutura fiscal - neste caso, uma tendência demográfica de longo prazo e mudanças incrementais na regra de elegibilidade do benefício social - mostraram-se determinantes para que uma política redistributiva no nível interpessoal pudesse produzir efeitos colaterais no processo de redistribuição de recursos entre regiões.

É preciso problematizar, no entanto, quais as implicações e limites dos resultados aqui reportados. Primeiramente, reconhecemos as limitações de caráter empírico que impedem estimativas mais precisas do número de indivíduos que efetivamente acessaram o BPC no período investigado. A este respeito vale ressaltar, por exemplo, a ausência de dados censitários sobre a população de indivíduos deficientes que inviabiliza o mapeamento das tendências sociodemográficas deste grupo, e a dificuldade de precisar quantos indivíduos idosos e vulneráveis foram efetivamente expostos à política em cada ponto do tempo. Em segundo lugar, a discricionariedade dos burocratas de nível de rua (Lipsky 1993) que avaliam a severidade da deficiência dos indivíduos que tentam acessar o benefício pode afetar o grau de focalização da política em cada região. Este é um aspecto de difícil mensuração e que escapa aos controles utilizados no presente trabalho.

Em terceiro lugar, no que diz respeito à validação e à capacidade de extrapolação dos resultados, faz-se necessário que outras políticas com características similares sejam avaliadas. Neste sentido, análises que considerem outros níveis de agregação das políticas - municípios e estados - podem contribuir para a validação dos resultados aqui reportados em caráter exploratório. Por fim, vale ressaltar que não é possível depreender, a partir das nossas evidências, que políticas centralizadas nunca operem, simultaneamente, redistribuição de recursos entre indivíduos e regiões. Nossos resultados apenas indicam que os fluxos redistributivos entre indivíduos e regiões devem, a priori, ser tomados como eventos independentes. A fronteira entre as duas interpretações está colocada pela diferença entre os conceitos de desigualdade e redistribuição.

Conquanto estas ressalvas devam ser consideradas, as evidências apresentadas neste trabalho permitem concluir que o problema de desigualdade territorial persiste no Brasil, dado que as regiões continuam a contribuir de maneira bastante desigual para parcela total de pobreza verificada. A adoção de políticas centralizadas que redistribuem recursos no nível individual não implica redução automática da desigualdade entre regiões. No que tange à realidade social, se apegar a automatismos pode significar a desconsideração de fenômenos que produzem importantes implicações para o resultado observado das políticas públicas.

Victor Araújo (victor.asaraujo@usp.br) é Doutorando em Ciência Política na Universidade de São Paulo e Pesquisador Junior do Centro de Estudos da Metrópole (CEM/CEPID). Vínculo institucional: Programa de Pós-graduação em Ciência Política, USP, São Paulo, SP, Brasil.

Paulo Flores (paulo.flores@ usp.br) é Mestrando em Ciência Política na Universidade de São Paulo e Pesquisador Junior do Centro de Estudos da Metrópole (CEM/CEPID). Vínculo Institucional: Programa de Pós-graduação em Ciência Política, USP, São Paulo, SP, Brasil.

\section{Referências}

Allen, J. \& Cochrane, A., 2007. Beyond the Territorial Fix: Regional Assemblages, Politics and Power. Regional Studies, 41(9), pp.1161-1175. DOI: 10.1080/00343400701543348

Anand, S. \& Sen, A., 1997. Concepts or Human Development and Poverty! A Multidimensional Perspective. Human Development Papers. United Nations.

Aquino, F.T.M. \& Cabral, B.E.S., 2002. O idoso e a família. In E.V. Freitas \& L. Py, ed. Tratado de Geriatria e Gerontologia. Rio de Janeiro: Guanabara Koogan. 
Araújo, N.; Barone, L. \& Alves de Brito, M., 2015. Mercado e mercantilização do trabalho no Brasil (1960-2010). In M. Arretche, ed. Trajetórias das Desigualdades: como o Brasil mudou nos últimos cinquenta anos. São Paulo: Editora Unesp.

Araújo, V., 2015. Federalismo, centralização e diferenças regionais: o padrão de desigualdade das políticas não reguladas do Brasil pós-1988. Perspectivas em Políticas Públicas, 8(15), pp.63-99. DOI: 10.2139/ssrn.2515377

Arretche, M., 2010. Federalismo e igualdade territorial: uma contradição em termos. Dados, 53(3), pp.587-620. DOI: $10.1590 / \mathrm{s} 0011-52582010000300003$

Avery, R.; Speare Jr., A. \& Lawton, L., 1989. Social Support, Disability and Independent Living of Elderly Person in the United States. Journal of Aging Studies, 3(4), pp.279-293. DOI: 10.1016/0890-4065(89)90002-9

Azzoni, C.R., 1997. Concentração regional e dispersão das rendas per capita estaduais: análise a partir de séries históricas estaduais de PIB, 1939-1995. Estudos Econômicos, 27(3), pp.341-393.

,2001. Economic Growth and Regional Income Inequality in Brazil. The Annals of Regional Science, 35(1), pp.133-152. DOI: $10.1007 / \mathrm{s} 001680000038$

Bacelar, T.A., 2000. A “questão regional” e a “questão nordestina”. In M.C. Tavares, ed. Celso Furtado e o Brasil. Rio de Janeiro: Paz e Terra.

Barros, R.; Corseuil, C.H. \& Leite, P.G., 2000. Mercado de trabalho e pobreza no Brasil. Desigualdade e pobreza no Brasil. Rio de Janeiro: IPEA.

Barros, R.; Foguel, M.N.O. \& Ulyssea, G.O., eds. 2007. Desigualdade de renda no Brasil: uma análise da queda recente. Brasília: IPEA.

Barros, R.; Carvalho, M. \& Franco, S., 2007. O papel das transferências públicas na queda recente da desigualdade de renda brasileira. In R. Barros; M.N.O. Foguel \& G.O. Ulyssea, eds. Desigualdade de renda no Brasil: uma análise da queda recente. Brasília: IPEA.

Beramendi, P., 2007. Inequality and the Territorial Fragmentation of Solidarity. International Organization, 61(4), pp.783-820. DOI: 10.1017/s0020818307070270

, 2012. The Political Geography of Inequality: Regions and Redistribution. Cambridge, UK: Cambridge University Press.

Beramendi, P. \& Rueda, D., 2014. Inequality and Institutions: The Case of Economic Coordination. Annual Review of Political Science, 17(1), pp.251-271. DOI: 10.1146/annurev-polisci-032211-210535

Bongaarts, J. \& Zimmer, Z., 2002. Living Arrangements of Older Adults in the Developing World: An Analysis of Demographic and Health Survey Household Surveys. Journal of Gerontology, 57(3), pp.S145-S157. DOI: 10.1093/geronb/57.3.s145

Brito, F., 2007. A transição demográfica no Brasil: as possibilidades e os desafios para a economia e a sociedade. Texto para Discussão, 318. Cedeplar.

Buchanan, J.M., 1995. Federalism as an Ideal Political Order and an Objective for Constitutional Reform. Publius: The Journal of Federalism, 25(2), pp.19-28. DOI: 10.1093/oxfordjournals.pubjof.a038192

Camargos, M.C.S.; Machado, C.J. \& Rodrigues, R.N., 2006. A relação entre renda e morar sozinha para idosas mineiras, 2003. In Seminário sobre a Economia Mineira. Diamantina.

Cameron, L., 2000. The Residency Decision of Elderly: A Nested Logit Analysis. Demography, 37(1), pp.17-27. DOI: $10.2307 / 2648093$

Cano, W., 2000. Celso Furtado e a questão regional no Brasil. In M.C. Tavares, ed. Celso Furtado e o Brasil. Rio de Janeiro: Paz e Terra.

Carvalho, J.A., 2004. Crescimento populacional e estrutura demográfica no Brasil. Texto para Discussão, 227. Cedeplar.

Cunha, J.M.P., 2015. A migração interna no Brasil nos últimos 50 anos: (des)continuidades e rupturas. In M. Arretche, ed. Trajetórias das Desigualdades: como o Brasil mudou nos últimos cinquenta anos. São Paulo: Editora Unesp.

Esping-Andersen, G., 1985. Power and Distributional Regimes. Politics \& Society, 14(2), pp.223-256. DOI: 10.1177/003232928501400204

Fajnzylber, P., 2001. Minimum Wage Effects throughout the Wage Distribution: Evidence from Brazil's Formal and Informal Sectors. Cedeplar. Digit.

Ferreira, P.C., 2004. Regional Policy in Brazil: A Review. Commissioned Paper. World Bank.

Flores, P., 2017. A política da política de salário mínimo no Brasil. Dissertação. São Paulo: Universidade de São Paulo.

Furtado, C.A., 1959. Operação Nordeste. Rio de Janeiro: Ministério da Educação e Cultura/ISEB.

Gradus, Y., 1983. The Role of Politics in Regional Inequality: The Israeli Case. Annals of the Association of American Geographers, 73(3), pp.388-403. DOI: 10.1111/j.1467-8306.1983.tb01424.x

Hoffmann, R., 2006. Transferências de renda e a redução da desigualdade no Brasil e cinco regiões entre 1997 e 2004 . Revista Econômica, 8(1), pp.55-81.

Kageyama, A. \& Hoffmann, R., 2006. Pobreza no Brasil: uma perspectiva multidimensional. Economia e Sociedade, 15(1), pp.79-112.

Kakwani, N. \& Son, H., 2008. Poverty Equivalent Growth Rate. Review of Income and Wealth, 54(4), p. 643-655. DOI: 10.1111/j.1475-4991.2008.00293.x

Kazepov, Y. \& Barberis, E., 2013. Social Assistance Governance in Europe: Towards a Multilevel Perspective. In Y. Kazepov, ed. Minimum Income Protection in Flux. London: Palgrave Macmillan. 
Kinsella, K. \& Velkoff, V.A., 2001. Living Arrangements. In K. Kinsella \& V.A. Velkoff, eds. An Aging Word: 2001. Washington: U.S. Government Printing Office.

Lemos, S., 2001. The Effects of the Minimum Wage on Wages and Employment in Brazil - A Menu of Minimum Wage Variables. University College London. Digit.

Levy, A. \& Chowdhury, K., 1995. A Geographical Decomposition of Intercountry Income Inequality. Comparative Economic Studies, 37(4), pp.1-17. DOI: 10.1057/ces.1995.38

Lipsky, M., 1993. Street-Level Bureaucracy: An Introduction. In M. Hill, ed. The Policy Process: A Reader. London: Routledge.

Manso, C.A.; Barreto, F.A. \& França, J.M., 2010. Retornos da educação e o desequilíbrio regional no Brasil. Revista Brasileira de Economia, 64(2), p.115-133. DOI: 10.1590/s0034-71402010000200003

Manso, C.A.; Barreto, F.A. \& Tebaldi, E., 2006. O desequilíbrio regional brasileiro: novas perspectivas a partir das fontes de crescimento pró-pobre. Revista Econômica do Nordeste, 37(3), pp.307-328.

Medeiros, M.; Diniz, D. \& Squinca, F., 2006. Transferências de renda para a população com deficiência no Brasil: uma análise do Benefício de Prestação Continuada. Textos para Discussão, 1184. Instituto de Pesquisa Econômica Aplicada.

Medeiros, M.; Souza, P. \& Castro, F.A., 2015a. A estabilidade da desigualdade de renda no Brasil, 2006 a 2012: estimativa com dados do imposto de renda e pesquisas domiciliares. Ciência \& Saúde Coletiva, 20(4), pp.971-986. DOI: $10.2139 /$ ssrn.2493877

, 2015b. O topo da distribuição de renda no Brasil: primeiras estimativas com dados tributários e comparação com pesquisas domiciliares. Dados, 58(1), pp.7-36. DOI: 10.1590/00115258201537

Menezes Filho, N. \& Kirschbaum, C., 2015. Educação e Desigualdade no Brasil. In M. Arretche, ed. Trajetórias das Desigualdades: como o Brasil mudou nos últimos cinquenta anos. São Paulo: Editora Unesp.

Mesquita, A.; Silva, C.; Silva, E. \& Oliveira, R. 2015. Assistência Social. In A.A. Valadares et al. eds. Boletim Políticas Sociais: Acompanhamento e Análise. V.23. Brasília: Instituto de Pesquisa Econômica Aplicada.

Milá, M.M., 2015. Income Concentration in a Context of Late Development: An Investigation of Top Incomes in Brazil using Tax Records, 1933-2013. Dissertação. Paris: Paris School of Economics.

Miranda, G.L., 2013. O ciclo de política como campo estratégico: o caso do benefício de prestação continuada. Dados, 56(2), pp.439-482. DOI: 10.1590/s0011-52582013000200007

Nasri, F., 2008. O envelhecimento populacional no Brasil. Einstein, 6(1), pp.S4-S6.

Neri, M.C., 2011. A nova classe média: o lado brilhante da base da pirâmide. São Paulo: Editora Saraiva.

Padovano, F., 2007. The Politics and Economics of Regional Transfers: Decentralization, Interregional Redistribution and Income Convergence. Cheltenham: Edward Elgar Publishing.

Resende, G.M.; Da Mata, D. \& Carvalho, A., 2007. Crescimento pró-pobre e distribuição de renda das capitais dos estados brasileiros. In A.X.Y. Carvalho et al. eds. Ensaios de Economia Regional e Urbana. Brasília: IPEA.

Rocha, S., 1998. Desigualdade regional e pobreza no Brasil: a evolução-1981/95. Texto para discussão, 567. Instituto de Pesquisa Econômica Aplicada. , 2010. Pobreza no Brasil. Crescimento, renda e pobreza. Como ficam os pobres? In XXII Fórum Nacional, Instituto Nacional de Altos Estudos. Rio de Janeiro.

,2013. Pobreza no Brasil: a evolução de longo prazo (1970-2011). In XXV Fórum Nacional, Instituto Nacional de Altos Estudos. Rio de Janeiro.

Saad, P.M., 2004. Transferências de apoio intergeracional no Brasil e na América Latina. In A.A. Camarano, ed. Os novos idosos brasileiros: muito além dos 60? Rio de Janeiro: IPEA.

Saboia, J., 2007. Efeitos do salário mínimo sobre a distribuição de renda no Brasil no período 1995/2005-resultados de simulações. Revista Econômica, 9(2), pp.1-25. 2014. Baixo crescimento econômico e melhora do mercado de trabalho-Como entender a aparente contradição? Estudos Avançados, 28(81), pp.115-125. DOI: 10.1590/s0103-40142014000200008

Sátyro, N. \& Cunha, E., 2014. The Path of Brazilian Social Assistance Policy Post-1988: The Significance of Institutions and Ideas. Brazilian Political Science Review, 8(1), pp.80-108. DOI: 10.1590/1981-38212014000100004

Sátyro, N. \& Soares, S., 2009. Análise do impacto do Programa Bolsa Família e do Benefício de Prestação Continuada na Redução da desigualdade nos estados brasileiros: 2004 a 2006. Texto para Discussão, 1435. Instituto de Pesquisa Econômica Aplicada.

Sen, A., 1973. On Economic Inequality. Oxford: Oxford University Press. , 1992. Inequality Reexamined. Oxford: Oxford University Press.

Silveira-Neto, R.M. \& Azzoni, C.R., 2012. Social Policy as Regional Policy: Market and Nonmarket Factors Determining Regional Inequality. Journal of Regional Science, 52(3), pp.433-450. DOI: 10.1111/j.1467-9787.2011.00747.x

Soares, S., 2002. O impacto distributivo do salário mínimo: a distribuição individual dos rendimentos do trabalho. Texto para Discussão, 873. Instituto de Pesquisa Econômica Aplicada. ,2009. Metodologias para estabelecer a linha de pobreza: objetivas, subjetivas, relativas e multidimensionais. Texto para Discussão, 1381. Instituto de Pesquisa Econômica Aplicada.

,2012. Bolsa Família, Its Design, Its Impacts and Possibilities for the Future. Working Paper. International Policy Centre for Inclusive Growth.

Soares, S.; Souza, L.R; Silva, W.J; Silveira, F.G., 2015. Perfil da Pobreza: Norte e Nordeste Rurais. Brasília: Centro Internacional de Políticas para o Crescimento Inclusivo. 
Souza, C., 2005 Federalismo, desenho constitucional e instituições federativas no Brasil pós-1988. Revista de Sociologia e Política, 24, pp.105-122. DOI: 10.1590/s0104-44782005000100008

Summa, R., 2015. Mercado de trabalho e a evolução dos salários no Brasil. Revista da Sociedade Brasileira de Economia Política, 42, pp.1-16.

Tiebout, C., 1956. A Pure Theory of Local Expenditures. The Journal of Political Economy, 64(5), pp.416-424. DOI: $10.1086 / 257839$

Treisman, D., 2007. The Architecture of Government: Rethinking Political Decentralization. Cambridge, UK: Cambridge University Press.

Vainer, C.B., 2011. Planejamento territorial e projeto nacional: os desafios da fragmentação. Revista Brasileira de Estudos Urbanos e Regionais, 9(1), pp.9-23. DOI: 10.22296/2317-1529.2007v9n1p9

Voigt, S. \& Blume, L., 2012. The Economic Effects of Federalism and Decentralization a Cross-Country Assessment. Public Choice, 151(1-2), pp.229-254. DOI: 10.1007/s11127-010-9745-z

Weingast, B.R., 1995. The Economic Role of Political Institutions: Market-Preserving Federalism and Economic Development. Journal of Law, Economics, \& Organization, Apr., pp.1-31. DOI: 10.1093/oxfordjournals.jleo.a036861

Wibbels, E., 2005. Decentralized Governance, Constitution Formation, and Redistribution. Constitutional Political Economy, 16(2), pp.161-188. DOI: 10.1007/s10602-005-2234-6

Wildavsky, A., 1985. Federalism Means Inequality. Society, 22(2), pp.42-49. DOI: 10.1007/bf02695380

Wong, L. \& Carvalho, J.A., 2006. O rápido processo de envelhecimento populacional do Brasil: sérios desafios para as políticas públicas. Revista Brasileira de Estudos de População, 23(1), pp.5-26. DOI: 10.1590/s0102-30982006000100002

\section{Outras fontes}

Brasil, 1995. Decreto no 1.744, de 8 de dezembro, de 1995. Regulamenta o benefício de prestação continuada devido à pessoa portadora de deficiência e ao idoso, de que trata a Lei no 8.742, de 7 de dezembro de 1993, e dá outras providências. Brasília.

Brasil, 2015. Constituição da república Federativa do Brasil. Brasília: Congresso Nacional.

DIEESE, 2015. Salário mínimo nominal e necessário. Disponível em: https://www.dieese.org.br/analisecestabasica/salarioMinimo.html. Acesso em: 22 ago. 2017.

Ministério da Saúde, 2012. Informações de Saúde (TABNET). Portal da Saúde. Disponível em: http://www.datasus.gov.br/DATASUS/index.php?area=0206. Acesso em: 22 ago. 2017.

Ministério do Desenvolvimento Social, 2015. Benefício assistencial ao idoso e à pessoa com deficiência (BPC). Disponível em: http://mds.gov.br/assuntos/assistencia-social/beneficios-assistenciais/bpc. Acesso em: 22 ago. 2017. 
Income Redistribution, Poverty, and Territorial Inequality in Brazil

\begin{abstract}
Can centralized redistributive policies lead to unequal results among territories? This study gives an affirmative answer to this question and presents evidences that the redistribution of income at the interpersonal level, promoted by social policy in which both revenue and expenditure are centralized - Benefício de Prestação Continuada (BPC) (Continuous Cash Benefit Payment) - is not automatically translated into redistribution of funds among territories. Although the adoption of income transfer policies in the interpersonal level is important to reduce overall regional poverty, the welfare gains do not necessarily mean a reduction of the interregional disparities in Brazil. In circumstances where exogenous factors affect the equalizing effect of income spending - when spending does not follow the spatial distribution of necessity (social vulnerability concentration), centralized redistributive policies can contribute to the increase in territorial inequality.
\end{abstract}

KEYWORDS: Public policies; income transfer; fiscal structure; social vulnerability; poverty.

This is an Open Access article distributed under the terms of the Creative Commons Attribution Non-Commercial License which permits unrestricted non-commercial use, distribution, and reproduction in any medium provided the original work is properly cited. 